\title{
Amine-grafted Walnut Shell for Efficient Removal Phosphate and Nitrate from Aqueous Solution
}

\section{Evans Dovi}

Zhengzhou University

\section{Aaron Albert Aryee}

Zhengzhou University

Jianjun Li

Zhengzhou University

Zhaohui Li

Zhengzhou University

\section{Lingbo Qu}

Zhengzhou University

Runping Han ( $\nabla$ rphan67@zzu.edu.cn )

Zhengzhou University https://orcid.org/0000-0002-1585-4522

\section{Research Article}

Keywords: modified walnut shell, Isotherms, Adsorption, Nitrate, Phosphate

Posted Date: June 16th, 2021

DOI: https://doi.org/10.21203/rs.3.rs-591132/v1

License: (c) (1) This work is licensed under a Creative Commons Attribution 4.0 International License. Read Full License 


\section{Amine-grafted Walnut Shell for Efficient Removal Phosphate and Nitrate from Aqueous Solution}

2 Evans Dovi, Aaron Albert Aryee, Jianjun Li, Zhaohui Li*, Lingbo Qu, Runping Han*

3 College of Chemistry, Green Catalysis Center, Zhengzhou University, No 100 of Kexue Road, Zhengzhou, 450001

4 P. R. China

$5 \quad{ }^{*}$ Corresponding authors. E-mail address: zhaohui.li@zzu.edu.cn (Z. Li), rphan67@zzu.edu.cn (R. Han)

6 Abstract The presence of emerging pollutants such as $\mathrm{PO}_{4}{ }^{3-}$ and $\mathrm{NO}_{3}{ }^{-}$in water bodies has attracted worldwide 7 concern about their severe effects on water bodies and the health of humankind in general. Therefore, to preserve the 8 health of humankind and environmental safety, it is of the essence that industrial effluents are treated before they are 9 discharged into water bodies. To accomplish this, the walnut shell was functionalized (ACWNS) with amine for 10 effective removal of $\mathrm{PO}_{4}{ }^{3-}$ and $\mathrm{NO}_{3}{ }^{-}$. Characterization studies of ACWNS were conducted using FTIR, XRD, XPS 11 and BET techniques. Removal of both ions was enhanced at lower temperature (293 K). The maximum uptake 12 capacity of phosphate and nitrate, at $293 \mathrm{~K}$, was 82.2 and $35.7 \mathrm{mg} \mathrm{g}^{-1}$, respectively. The primary mechanism by 13 which these ions were uptaken onto ACWNS could be electrostatic interactions and hydrogen bonding.Pseudo14 second-order kinetics fitted the $\mathrm{PO}_{4}{ }^{3}$ and $\mathrm{NO}_{3}{ }^{-}$adsorption, while Freundlich and Langmuir models best fitted the $15 \mathrm{PO}_{4}{ }^{3}$ and $\mathrm{NO}_{3}^{-}$adsorption, respectively. Furthermore, in the binary system, the uptake capacity of phosphate 16 decreased by $14.4 \%$ while nitrate witnessed a reduction in its uptake capacity by $10.4 \%$. So ACWNS has a higher 17 attraction towards both ions and this could be attributed to the existence of a variety of active areas on ACWNS that 18 exhibit a degree of specificity for the individual anions. Results obtained from real water samples analysis confirmed 19 ACWNS as highly efficient to be utilized for practical remediation processes.

20 Keywords: modified walnut shell; Isotherms; Adsorption; Nitrate; Phosphate 


\section{Introduction.}

Water is an indispensable element for the continued survival of humankind and other organisms in the ecosystem. Based on this, clean and quality water must be ensured for the survival of living organisms. However, pollutants emanating from activities such as agricultural and mining affect the integrity of these water systems. Large portions of these aquatic systems get polluted by wastewater containing dissolved nutrients. Phosphate and nitrate (nutrients) which are emerging pollutants stemming from livestock wastewater (Hamoudi and Belkacemi, 2013; Onyango et al., 2007), industrial wastewater, agricultural activities such as fertilization (Hamoudi and Belkacemi, 2013; Cheng et al., 2017) detergents manufacturing industries and mineral processing industries released into natural aquatic bodies have attracted attention lately (Hamoudi and Belkacemi, 2013;Cheng et al., 2017; Hamoudi et al., 2007)

The existence of these nutrients in aquatic systems is associated with several adverse health conditions such as diarrhoea, vomiting, hypertension, spontaneous abortions, respiratory tract infections (Cheng et al., 2017; Qiao et al., 2019), methemoglobinemia ("blue baby" syndrome) (Hamoudi et al., 2007). Furthermore, environmental conditions like Lake eutrophication have been a critical environmental problem, and nitrogen and phosphorus are widely regarded as major nutrients causing eutrophication in lakes. The introduction of vast volumes of nutrientsbearing wastes into surface water will promote the development of microbes and algae in most habitats, which can be detrimental to fish and other marine life, resulting in water quality degradation (Qiao et al., 2019). Again, the occurrence of eutrophication in water impedes penetration of light and decreases the oxygen content needed for the survival of aquatic organisms, hence imperilling them. It is therefore essential to treat effluent before it is discharged into the aquatic environment. According to the World Health Organization (2011), the allowable levels of phosphate and nitrate in portable water are $0.1 \mathrm{mg} \mathrm{L}^{-1}$ and $50 \mathrm{mg} \mathrm{L}^{-1}$, respectively. Consequently, efficient, inexpensive and practicable methods for nitrate and phosphate uptake are urgently required.

Numerous physicochemical and biological processes have been explored to get rid of these noxious wastes from wastewater before they are emptied into aquatic bodies. Amid these techniques, adsorption has been discovered as an efficient and effective process for treating wastewater owing to its straightforwardness, economical, green, appropriate for treating large amounts of water and associated with high efficiency, leading to less sludge production and minimal disposal problems. Traditional adsorbents and agricultural waste (AW) employed to remove phosphate and nitrate exhibited low adsorption capacities (Hamoudi and Belkacemi, 2013;Banu and Meenakshi, 2017). However, studies reveal that chemical or physical modification of AW adsorbent improves its adsorption capacity (Kani et al., 2021;Xu et al., 2012;Sowmya and Meenakshi, 2014). A classic instance is the CTAB functionalized walnut shell, which enhanced Congo red uptake substantially owing to the binding ability or ionic reaction between the functionalized sorbents and the anionic dye molecules, while there was also binding capacity toward Bisphenol A from solution (Dovi et al., 2021).

Previous works reveal that WNS was less utilized compared with other agricultural wastes such as peanut husk (Mpatani et al., 2021) rice husk, bagasse (Hamoudi and Belkacemi, 2013;Mpatani et al., 2020). However, WNS could be considered as a critical agricultural waste content as a result of its large production. Based on the 2019 report issued by the Food and agriculture organization of the United Nations (FAO), the world production of 
walnuts (in a shell) stood at 4.5 million tons with China contributing $56 \%$ and being the largest producer. Walnut production creates a considerable volume of waste, which is typically burnt or buried in a landfill as a result of its widespread use. The buried walnut shells take a longer period to decay because they are very hard and could become an irritant to the organisms in the environment (Zhao et al., 2020). However, when the wastes are burnt, they may contribute to global warming since a high amount of carbon dioxide may be produced as a result of the burning process. Consequently, using walnut shells, which are amply available, cheap, and its easiness to employ in the area of adsorption to purify contaminated water could be deemed safe ecologically (Li, 2020; Ren et al., 2016).

Herein, a cheap and effective adsorbent, ACWNS based on walnut shell, was successfully synthesized by grafting and cross-linking diethylenetriamine (DETA) and triethylamine (TEA) with epichlorohydrin (ECH) and N, $\mathrm{N}$-dimethylformamide (DMF) for the uptake of phosphate and nitrate. In this research, ACWNS was used first time to bind phosphate and nitrate and examine its adsorption property and selectivity in a binary system, practicability using real water samples, the removal mechanism, uptake kinetics of the contaminants and established the various physicochemical properties on the removal rate and the uptake capacity of the adsorbent. The effect of contaminant concentration, $\mathrm{pH}$, dosage and temperature on uptake was studied.

\section{Materials and Methods}

\subsection{Materials}

Walnut shell (WNS) was acquired from a market close to Zhengzhou University. Potassium hydrogen Phosphate $\left(\mathrm{KH}_{2} \mathrm{PO}_{4}\right)$ was acquired from Aladdin Reagent Co., Ltd., epichlorohydrin (ECH), N,Ndimethylformamide (DMF), sodium hydroxide $(\mathrm{NaOH})$, triethylamine (TEA, merck), hydrochloric acid ( $\mathrm{HCl})$, sodium sulphate $\left(\mathrm{Na}_{2} \mathrm{SO}_{4}\right)$, Sodium chloride $(\mathrm{NaCl})$, potassium nitrate $\left(\mathrm{KNO}_{3}\right)$ and diethylenetriamine (DETA), were acquired from Aladdin Reagent Co., Ltd. Analytical graded chemicals were used.

\subsection{Preparation of ACWNS}

The Walnut shell (WNS) was prepared as described in our previous work (Dovi et al 2021). The prepration of ACWNS was slightly modified according to Xu et al., (2012). Brifely, $2.0 \mathrm{~g}$ of WNS was weighed in a $250 \mathrm{~mL}$ round bottom flask with $10 \mathrm{~mL}$ of epichlorohydrin $(\mathrm{ECH})$ and $12 \mathrm{~mL}$ of $\mathrm{N}, \mathrm{N}$-dimethylformamide (DMF). The mixture was then heated in an oil bath at $850 \mathrm{C}$ with continuous stirring for $1 \mathrm{~h}$. In the presence of organic solvents such as DMF, ECH reacted with the $-\mathrm{OH}$ groups available on cellulose or hemicelluloses of WNS, to form epoxy cellulose or hemicelluloses ethers. The obtained epoxy cellulose or hemicelluloses ethers was crossed-linked with $3.5 \mathrm{~mL}$ of diethylenetriamine (DETA) and the mixture stirred continuously for another $1 \mathrm{~h}$ at $85{ }^{\circ} \mathrm{C}$. This was followed by $10 \mathrm{~mL}$ of triethylamine (TEA) at $85{ }^{\circ} \mathrm{C}$ for $3 \mathrm{~h}$ with continuous stirring for the grafting procedure to occur. Lastly, the end-product was rinsed with deionized water to get rid of any residues until its $\mathrm{pH}$ becomes neutral and dried for $12 \mathrm{~h}$ at $80{ }^{\circ} \mathrm{C}$, grinded and filtered with 40-60 mesh to attain the size of particles desired, then stored to be used later. Finally, ACWNS were obtained and strored.

\subsection{Characterization techniques and instruments}

The existence of functional groups on ACWNS and WNS was determined from 4000-500 $\mathrm{cm}^{-1} \mathrm{using}^{\mathrm{Fourier}-}$ transform infrared (FTIR -Nicolet iS50, American). The crystalline structure of the absorbents was studied by Powder X-ray diffraction (XRD, PANalytical, Netherlands) while the Brunauer-Emmett-Teller technique (BET, 
ASAP2420-4MP, American ) was employed to determine the pore volume, specific surface area and average pore diameter. X-ray photoelectron spectroscopy (XPS, Escalab 250xi, England) was performed to establish the alteration and the uptake process. The scanning electron microscopy (SEM, Hitachi Su8020, Japan) was used to confirm the surface formation of WNS and ACWNS. The absorbance and equilibrium concentration of phosphate $\left(\mathrm{PO}_{4}{ }^{3-}\right)$ and nitrate $\left(\mathrm{NO}_{3}{ }^{-}\right)$were quantified on a UV-Vis spectrophotometer (Persee TU-1900, China) at 700 and $220 \mathrm{~nm}$, respectively. The $\mathrm{pH}$ point of zero charge $\left(\mathrm{pH}_{\mathrm{zpc}}\right)$ of WNS and ACWNS were conducted using the procedure prescribed by Meili et al., (2019)

\subsection{Batch adsorption experiments}

The removal experiment was conducted using a single component method. Preliminary experiments revealed that the optimum adsorbent dose was $1.0 \mathrm{~g} \mathrm{~L}^{-1}$ (Fig. 4). $0.010 \mathrm{~g}$ ACWNS and $10 \mathrm{~mL}$ of adsorbate were placed in a $50 \mathrm{~mL}$ conical flask and agitated at $130 \mathrm{rpm}$. The adsorption kinetics was studied at $30 \mathrm{mg} \mathrm{L}^{-1}$ as the initial concentration of $\mathrm{PO}_{4}{ }^{3-}$ and $\mathrm{NO}_{3}{ }^{-}$at $303 \mathrm{~K}$, while uptake equilibrium experiments were performed at different $\mathrm{PO}_{4}{ }^{3-}$ and $\mathrm{NO}_{3}{ }^{-}$concentrations $\left(10-100 \mathrm{mg} \mathrm{L}^{-1}\right)$ at $293,303,313 \mathrm{~K}$ and the experimental time of $1 \mathrm{~h}$ was adequate to bring the reaction to equilibrium. The samples were consequently centrifuged at $5000 \mathrm{rmp}$ for $5 \mathrm{~min}$ and the clear solution was taken. For the adsorption work in binary systems, $1.0 \mathrm{~g} \cdot \mathrm{L}^{-1}$ ACWNS was placed in a $50 \mathrm{~mL}$ flask containing a solution mixture of initial concentrations of $\mathrm{PO}_{4}{ }^{3-}$ and $\mathrm{NO}_{3}{ }^{-}$at 1:1 ratio. The method and analysis for the binary system was the same as illustrated above, and the experimental time was $1 \mathrm{~h}$. All the works were carried out three times and their means were put to data analysis. $\mathrm{PO}_{4}{ }^{3-}$ concentration was determined at $700 \mathrm{~nm}$ using a UV-Vis spectrophotometer (via Mo-Tb anti spectrophotometry) while $\mathrm{NO}_{3}{ }^{-}$concentration was directly measured at $220 \mathrm{~nm}$ using a UV-Vis spectrophotometer. The removal efficiency and amount of $\mathrm{PO}_{4}{ }^{3-}$ or $\mathrm{NO}_{3}{ }^{-}$adsorbed on a unit weight of adsorbent ( $q_{\mathrm{e}}$ or $q_{\mathrm{t}}, \mathrm{mg} \mathrm{g}^{-1}$ ) was calculated from Eq. (1) and Eq. (2).

$$
P=\frac{\left(C_{0}-C_{\mathrm{e}}\right)}{C_{0}} \times 100 \%
$$

$$
q=\frac{V\left(C_{0}-C\right)}{m}
$$

where $C_{0}$ means the initial adsrobate concentration $\left(\mathrm{mg} \mathrm{L}^{-1}\right)$ whereas $C, V$ and $m$ represent the concentration of the adsorbate at any time $t$ or equilibrium $\left(\mathrm{mg} \mathrm{L}^{-1}\right)$, the volume of adsorbate solution $(\mathrm{L})$ and mass of adsorbent $(\mathrm{g})$, respectively.

\subsection{Application to the Treatment of Real Water Samples}

To evaluate the practical prospects of ACWNS, a real environmental sample was analyzed. Water samples from a lake on Zhengzhou university campus and tap water were sampled for the analysis. These real samples were spiked with varied concentrations $\left(5,10\right.$ and $20 \mathrm{mg} \mathrm{L}^{-1}$ ) of both $\mathrm{PO}_{4}{ }^{3-}$ and $\mathrm{NO}_{3}{ }^{-}$separately. The study was then performed by placing $10 \mathrm{mg}$ of ACWNS into $10 \mathrm{~mL}$ of spiked and unspiked samples of the lake and tap water separately and mixtures shaken at $303 \mathrm{~K}$ for $1 \mathrm{~h}$ in an orbital shaker. This study was conducted in a singlecomponent system.

\subsection{Reusability studies of ACWNS}


To estimate the regeneration capability of ACWNS towards $\mathrm{PO}_{4}{ }^{3-}$ and $\mathrm{NO}_{3}{ }^{-}$adsorption, desorption and regeneration experiments were effected in batch mode. Initially, $10 \mathrm{mg}$ of ACWNS was separately placed in a 50 $\mathrm{mL}$ flask containing $30 \mathrm{mg} \mathrm{L}^{-1} \mathrm{PO}_{4}{ }^{3-}$ and $\mathrm{NO}_{3}{ }^{-}$solution at $303 \mathrm{~K}$. The mixture was shaken at $130 \mathrm{rmp}$ for $1 \mathrm{~h}$ in an orbital shaker. Consequently, the spent ACWNS was desorbed using $10 \mathrm{~mL}$ of $0.1 \mathrm{~mol} \mathrm{~L}^{-1} \mathrm{NaOH} 0.1 \mathrm{~mol} \mathrm{~L}^{-1}$ $\mathrm{NaOH}-\mathrm{NaCl}, 0.1 \mathrm{~mol} \mathrm{~L}^{-1} \mathrm{HCl}$ as an elution solution. Furthermore, the reuse ability of ACWNS was verified by conducting reusability studies at the same uptake conditions in three successive cycles. The regeneration outcome was achieved as the ratio of values of $q_{\mathrm{e}}$ before and $q_{\mathrm{e}}$ after regeneration.

\section{Results and discussion}

\subsection{Characterization of Adsorbent (ACWNS)}

\subsubsection{Fourier-transform infrared Analysis}

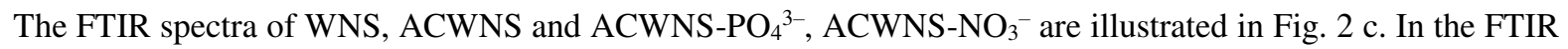
spectrum of WNS, ACWNS and ACWNS-PO ${ }_{4}^{3-}, \mathrm{ACWNS}-\mathrm{NO}_{3}{ }^{-}$, the band spanning from $3400-3500 \mathrm{~cm}^{-1}$ was due to $-\mathrm{OH} /-\mathrm{NH}$ stretching vibrations depicting hydrogen bonds which may be due to compounds like carboxylic acids and alcohols as in cellulose, lignin and pectin. Hence, it divulges the presence of $-\mathrm{OH}$ groups on the adsorbent's surface (Foroughi-Dahr et al., 2015). Also, the absorption peaks observed around $2900 \mathrm{~cm}^{-1}$ on the adsorbents could be credited to the presence of $\mathrm{CH}_{2}$ groups. The new peak which appeared around $1330 \mathrm{~cm}^{-1}$ on ACWNS matched up to $\mathrm{C}-\mathrm{N}$ bending vibrations, that pointed to the existence of amine groups (Ren et al., 2016). The FTIR analysis of ACWNS-PO ${ }_{4}^{3-}$ reveals that peaks ranging from $1050 \mathrm{~cm}^{-1}$ to $1646 \mathrm{~cm}^{-1}$ were improved owing to the uptake of $\mathrm{PO}_{4}{ }^{3-}$ , corresponding to the $-\mathrm{P}-\mathrm{O}$ and $-\mathrm{O}-\mathrm{P}-\mathrm{O}$ groups. It showed that the phosphate group was successfully adsorbed

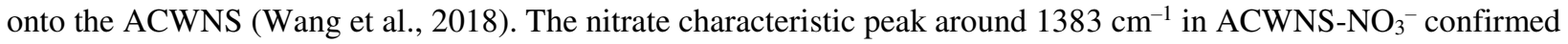
the adsorption of nitrate by ACWNS (Xu et al., 2013). FTIR analysis established the existence of functional groups and demonstrated that ACWNS could adsorb nutrients from aqueous medium.

\subsubsection{X-ray Diffraction Analysis}

The XRD analysis of WNS and ACWNS is exhibited in Fig. 2 d. XRD peaks of WNS around $2 \theta=17.5^{\circ}, 22.5^{\circ}$ and $35^{\circ}$ signify the presence of a highly organized crystal cellulose structure (Wada et al., 2004). The same peak on ACWNS was observed but with a slight shift to $21.88^{\circ}$. Again, the XRD peaks around $2 \theta=17.5^{\circ}$ and $35^{\circ}$ disappeared, confirming the successful modification. However, the results showed that the modification had no effect on the structure and crystal nature of the WNS (Sowmya and Meenakshi, 2014)

\subsubsection{Brunauer-Emmett-Teller Analysis}

The BET surface area was estimated to be 0.230 and $0.369 \mathrm{~m}^{2} \mathrm{~g}^{-1}$ for WNS and ACWNS, respectively. The polymerization seems to enlarge the surface area and also increased the average pore size of the adsorbent from 17.8 (WNS) to $32.7 \mathrm{~nm}$ (ACWNS). This could be ascribed to a decrease in the number of hydroxyl groups on WNS as they react actively with amine groups under excessive heat causing the widening of the pores sited in WNS (Ribeiro et al., 2019; Mpatani et al., 2020). The textural characteristics of ACWNS influenced the interactions between the adsorbent and pollutants, as a result increasing the adsorption quantity of both phosphate and nitrate. Fig. 3d depicts the graph obtained from the adsorption and desorption of $\mathrm{N}_{2}$ gas on the surface of ACWNS.

\subsubsection{Scanning Electron Microscopy Analysis}


The SEM of WNS and ACWNS are describeed in Fig. 2a and b. The surface structure of ACWNS is relatively diverse compared to WNS. The decrease in the particle size and irregular surface of ACWNS may be credited to the quaternization of WNS. The uneven and pores available on the surface of ACWNS might have functioned as the active sites in the adsorption of phosphate and nitrate.

\subsubsection{Point of zero charge}

172 The $\mathrm{pH}$ value at which the adsorbet's surface is neutral is known as the point of zero charge. It depicts the state of the absorbent's surface when the overall charge on it is zero. (Zhao et al., 2019). It verifies how easily a material can uptake potential injurious ions. Therefore, it is indispensable to assess pHzpc of WNS and ACWNS. The outcome is presented in Fig. 3c. It is observed from Fig. 3c that the pHzpc of WNS and ACWNS were 6.4 and 6.0 respectively. Below these values, the charge on the surface is positive, while above those values, the charge is negative. Hence, it was anticipated that the removal would occur at $\mathrm{pH}$ lower than 6.4 and 6.0, since phosphate and nitrate are anionic species. However, ACWNS is a novel adsorbent that efficiently adsorbed both nutrients (phosphate and nitrate) over a broad array of $\mathrm{pH}(3-10)$ as exhibited in Fig 3 a and b. Hence, the $\mathrm{pH}$ of the solutions was not altered but was used as prepared for the adsorption experiments.

\subsection{Adsorption Studies}

\subsubsection{Influence of $\mathrm{pH}$ on adsorption capacity}

In the adsorption process, the degree of ionization, the adsorbent's surface charge and the speciation of adsorbates can greatly be affected by the $\mathrm{pH}$ of the solution. Hence, the adsorption was studied at different $\mathrm{pH}$ (212) to arrive at the most favourable $\mathrm{pH}$ for the uptake process. The influence of $\mathrm{pH}$ on the uptake of $\mathrm{PO}_{4}{ }^{3-}$ and $\mathrm{NO}_{3}{ }^{-}$ is shown in Fig. 3a and b. It was clearly observed from Fig. 3a and b that $\mathrm{PO}_{4}{ }^{3-}$ and $\mathrm{NO}_{3}{ }^{-}$adsorption capacities were enhanced as the initial $\mathrm{pH}$ was raised from 2.0 to 3.0 and stayed considerably constant (up to $\mathrm{pH} 10.0$ and 9.0 for $\mathrm{PO}_{4}{ }^{3-}$ and $\mathrm{NO}_{3}{ }^{-}$, respectively), and then reduced significantly as $\mathrm{pH}$ increased further from 10.0 to 12.0. The best uptake occurred between $\mathrm{pH} 3$ and 10 for $\mathrm{PO}_{4}{ }^{3-}$ and 3 to 9 for $\mathrm{NO}_{3}{ }^{-}$ions. The results also indicated that in a highly acidic medium, removal of $\mathrm{NO}_{3}^{-}$was slightly enhanced compared to the uptake of $\mathrm{PO}_{4}{ }^{3-}$ as exhibited in Fig. 3 a and b, which is similar to studies conducted by Qiao et al., (2019). These occurrences can be better elucidated by protonation and competing ions effects. The ionization constants (pKa) for $\mathrm{PO}_{4}{ }^{3-}$ in $\mathrm{H}_{2} \mathrm{PO}_{4}^{--}, \mathrm{HPO}_{4}{ }^{2-}, \mathrm{PO}_{4}{ }^{3-}$ forms, based on the $\mathrm{pH}$ of the solution ( $\mathrm{p} K_{1}=2.2, \mathrm{p} K_{2}=7.2, \mathrm{p} K_{3}=12.4$ ) respectively (Hamoudi et al., 2007). As reported, within this $\mathrm{pH}$ range of 3-10, phosphates are likely to exist in $\mathrm{H}_{2} \mathrm{PO}_{4}{ }^{-}$and $\mathrm{HPO}_{4}{ }^{2-}$ which are strongly attracted to the positively charged adsorbent; with this attraction decreasing with an increase in solution pH (Hamoudi et al., 2007). In an highly acidic medium, $\mathrm{PO}_{4}{ }^{3-}$ becomes protonated, forming $\mathrm{H}_{3} \mathrm{PO}_{4}$ which limits its adsorption. Again, the presence of a high concentration of $\mathrm{H}^{+}$ions competes for the uptake of $\mathrm{H}_{2} \mathrm{PO}_{4}^{-}$against a highly positive charged adsorbent surface, resulting in the formation of $\mathrm{H}_{3} \mathrm{PO}_{4}$ molecules.However, adsorption of $\mathrm{NO}_{3}{ }^{-}$was not affected by low $\mathrm{pH}$ as $\mathrm{HNO}_{3}$ is a strong electrolyte (Wang et al., 2018). Meanwhile, at $\mathrm{pH}$ greater than 10, a drastic decrease in the uptake of $\mathrm{PO}_{4}{ }^{3-}$ and $\mathrm{NO}_{3}{ }^{-}$was observed, which could be ascribed to excessive $\mathrm{OH}^{-}$ions competing with both $\mathrm{PO}_{4}{ }^{3-}$ and $\mathrm{NO}_{3}{ }^{-}$for the binding sites on the adsorbent's surface. Based on the results of the adsorption assay, the amine-cross linked walnut shell was shown to be most promising for use as an adsorbent to uptake $\mathrm{PO}_{4}{ }^{3-}$ and $\mathrm{NO}_{3}{ }^{-}$ 
cross-linked agricultural by-products (Xu et al., 2011; Kalaruban et al., 2016). Consequently, changing pH values of polluted solutions in a real sample would not be required. The $\mathrm{pH}$ values after the uptake of pollutants were also determined. For both anions, the results show that the equilibrium $\mathrm{pH}$ values were almost constant at the $\mathrm{pH}$ range of of 4.0 - 8.0. Similar results also accounted for a similar $\mathrm{pH}$ change when modified tea waste was used for $\mathrm{PO}_{4}{ }^{3-}$ removal (Qiao et al., 2019). This buffer effect could have resulted from the changing effect of nutrient species present in an aqueous solution.

\subsubsection{Effect of adsorbent dose}

Generally, the mass of adsorbent used is relative to the amount of binding site available for nutrient absorption $\left(\mathrm{PO}_{4}{ }^{3-}\right.$ and $\left.\mathrm{NO}_{3}{ }^{-}\right)$. As seen in Figure $4 \mathrm{a}$ and $\mathrm{b}$, the percentage reduction of $\mathrm{PO}_{4}{ }^{3-}$ and $\mathrm{NO}_{3}{ }^{-}$increased as the adsorbent mass increased from 0.5 to $3.0 \mathrm{~g} \mathrm{~L}^{-1}$. At higher doses, this dose-dependence may be attributed to increased surface area and a larger number of binding sites (Qiao et al., 2019; Banu and Meenakshi, 2017;Pan et al., 2014). At a dose of $1.0 \mathrm{~g} \mathrm{~L}^{-1}$ the uptake of $\mathrm{PO}_{4}{ }^{3-}$ was almost twice as that of $\mathrm{NO}_{3}{ }^{-}$, which was in agreement with work reported by Wang et al., (2018). However, ACWNS exhibited an excellent removal of nutrients as the dose increased. Conversely, the $q_{\mathrm{e}}$ values showed a reverse trend with the rise of dose, signifying that binding groups available on ACWNS were underexploited at a higher dose, that occurs as a consequence of the solution-adsorbent surface solute concentration gradient (Zhang et al., 2011). In contrast, at a dose of $1.0 \mathrm{~g} \mathrm{~L}^{-1}$ WNS showed very low removal ability with reference to ACWNS (Fig. 4 a and 4 b), hence, ACWNS was adopted and used for the remaining experiments.

\subsubsection{Effect of Salinity}

To estimate the feasibility of the prepared ACWNS for industrial application, it is imperative to evaluate the effect of salt ions on the uptake procedure to ascertain the expediency of ACWNS. In this work, the effects of $\mathrm{NaCl}$ and $\mathrm{Na}_{2} \mathrm{SO}_{4}$ on the uptake of $\mathrm{PO}_{4}{ }^{3-}$ and $\mathrm{NO}_{3}{ }^{-}$were examined at the same experimental conditions and the obtained results are shown in Fig. $4 \mathrm{c}$ and 4 d. The adsorption potential of ACWNS declined as the salt concentration was raised from $0.01 \mathrm{~mol} \mathrm{~L}^{-1}$ to $0.2 \mathrm{~mol} \mathrm{~L} \mathrm{~L}^{-1}$, as seen in Fig. 4 c. This development might be assigned to the competing effect between $\mathrm{PO}_{4}{ }^{3-}$ and salt ions $\left(\mathrm{Cl}^{-}\right.$and $\left.\mathrm{SO}_{4}{ }^{2-}\right)$ for the active groups present on the adsorbent, hence inhibiting $\mathrm{PO}_{4}{ }^{3-}$ uptake, which suggests that the mechanism of adsorption could be electrostatic interaction. In contrast, for the nitrate removal as illustrated in Fig $4 \mathrm{~d}$, the adsorption quantity of ACWNS was significantly increased in the presence of both $\mathrm{Cl}^{-}$and $\mathrm{SO}_{4}{ }^{2-}$. The increase was noticed to be greater than $40 \%$ of its initial uptake at a higher concentration of the salts. This suggests that other forces like hydropbobic interactions may be linked to the uptake of $\mathrm{NO}_{3}{ }^{-}$onto ACWNS besides the ionic force of attraction (Zhao et al., 2017). Again, this observation could be credited to the capability of these anions to lessen the boundary effect between the adsorbent and the nitrate molecules, thus leading to an enhanced interaction and accessibility to active sites.(Hu and Han, 2019).

\subsubsection{Effect of equilibrium concentration and fitting of isotherm models}

The adsorptions of $\mathrm{PO}_{4}{ }^{3-}$ and $\mathrm{NO}_{3}{ }^{-}$onto ACWNS at varied adsorbate concentration are presented in Fig $5 \mathrm{a}$ and b. The $q_{\mathrm{e}}$ values become bigger as the adsorbate equilibrium concentration $C_{\mathrm{e}}$, increases. However, the uptake capacity for both $\mathrm{PO}_{4}{ }^{3-}$ and $\mathrm{NO}_{3}{ }^{-}$decreased with increasing temperature, which suggests an exothermic reaction. 
241 investigate the adsorption experimental parameters. Adsorption isotherm basically, is an expression that helps to 242 establish the interactions between the adsorbent and adsorbate molecules at equilibrium (Cao et al., 2014) along with information about the adsorbent's surface characteristics, adsorption affinity, and adsorption mechanism (Leah et al., 2018). In this study, Langmuir (Eq. 3), Freundlich (Eq. 4) and Temkin (Eq. 5) were used to depict removal phenomenon. The Langmuir isotherm depicts homogeneous and monolayer adsorption onto a uniform surface (Aryee et al., 2021) the Freundlich model illustrates heterogeneous surface and multilayer form of adsorption. On the contrary, the Temkin isotherm model relates to the energy state resulting from material and nutrients reaction (Zhang et al., 2014).

$$
q_{\mathrm{e}}=K_{\mathrm{F}} C_{\mathrm{e}}^{1 / n}
$$

where $q_{\mathrm{m}}$ is the maximum adsorption quantity $\left(\mathrm{mg} \mathrm{g}^{-1}\right), \mathrm{K}_{\mathrm{L}}$ is the adsorption constant $\left(\mathrm{L} \mathrm{mg}^{-1}\right), q_{\mathrm{e}}$ is the equilibrium adsorption capacity $\left(\mathrm{mg} \mathrm{g}^{-1}\right), \mathrm{C}_{\mathrm{e}}$ is the concentration of nutrients at equilibrium $\left(\mathrm{mg} \mathrm{L}^{-1}\right) . K_{\mathrm{F}}$ is the adsorption quantity constant; $1 / n$ is the adsorption intensity constant; $A$ and $B$ are the Temkin constants.

The parameters of Langmuir, Freundlich and Temkin isotherms were obtained by evaluating the experimental data based on nonlinear regression analysis. The results and the fitted curves are shown in Table 1 and Fig. 5 (a and b) respectively. The experimental data presented in Table 1 indicated that uptake of phosphate onto ACWNS was was well fitted by the Freundlich isotherm models. Thus, the adsorption of phosphate onto ACWNS suggests multilayer heterogeneous removal of phosphate (Velazquez-jimenez et al., 2018). Moreover, from Table 1, the Freundlich equation presented the highest $\mathrm{R}^{2}$ values and lowest SSE values compared to both the Langmuir and Temkin equations. As a result, the Freundlich model best described phosphate removal onto ACWNS. Additionally, the fitted curves stemming from the Freundlich model were also very near to the experimental data relative to both Langmuir and Temkin models. Again, the acquired values of $1 / n(0.1<1 / n<1)$ signified favourable removal of phosphate at all temperatures studied (Zhu et al., 2011). Conversely, for the adsorption of nitrate, the Langmuir equation depicts higher $\mathrm{R}^{2}$ and lower SSE values compared to the Freundlich and Temkin equations as shown in Table 1. Additionally, the Langmuir fitted curves were close to the experimental results relative to Freundlich and Temkin curves (Fig.5 a and b). As a result, the Langmuir model was considered appropriate for describing nitrate adsorption onto the surface of ACWNS, as it illustrates monolayer adsorption. Also from Table 1, the values of $K_{\mathrm{L}}$ were lower than 1 suggesting that the bonding forces were strong and that the uptake was favorable (Aryee et al., 2021).The maximum adsorption capacity $\left(q_{m}\right)$ values for $\mathrm{PO}_{4}{ }^{3-}$ and $\mathrm{NO}_{3}{ }^{-}$were estimated using the Langmuir model, and the values of $q_{\mathrm{m}}$ for $\mathrm{PO}_{4}{ }^{3-}$ and $\mathrm{NO}_{3}{ }^{-}$were matched up with other reported adsorbents in previous works as illustrated in Table 2. The amine modified WNS (ACWNS) exhibited a higher performance at a dosage of $1.0 \mathrm{~g} \mathrm{~L}^{-1}$ than other adsorbent for removal of $\mathrm{PO}_{4}{ }^{3-}$ and $\mathrm{NO}_{3}{ }^{-}$. This outcome signified that ACWNS has immense potential to uptake $\mathrm{PO}_{4}{ }^{-}$and $\mathrm{NO}_{3}{ }^{-}$from contaminated water.

\subsubsection{Adsorption kinetic and fittig models}


In general, kinetic experiments were performed to further grasp the rate mechanism underlying the uptake phenomenon. The relationship between adsorption quantity of $\mathrm{PO}_{4}{ }^{3-}$ and $\mathrm{NO}_{3}{ }^{-}$onto ACWNS and the contact time at various temperatures $(293,303$ and $313 \mathrm{~K}$ ) are shown in Fig. $5 \mathrm{c}$ and d respectively. The kinetics trend can be illustrated in three steps. In the initial step, the sharp slope represented a fast reaction rate. During the second step, the reaction rate began to slow down in which the uptake processes were almost completed. The reaction rate in the further slowed down in the third stage further slowed down until the equilibrium was attained within $60 \mathrm{~min}$ for both anions. These occurrences could be explained by the fact that more active sites are available on ACWNS, as well as the fact that the high concentration gradient of the contaminants $\left(\mathrm{PO}_{4}{ }^{3-}\right.$ and $\left.\mathrm{NO}_{3}{ }^{-}\right)$decreased over time until equilibrium was reached within 60 minutes.Furthermore, as shown in Table 3, the total anions adsorbed by ACWNS decreased with increasing temperature, as an increased qe value was observed at the lowest temperature for both phosphate and nitrate.This study demonstrated that adsorption was an exothermic process (Zhang et al., 2014). The rate-determining phase and mechanism for absorption of $\mathrm{PO}_{4}{ }^{3-}$ and $\mathrm{NO}_{3}{ }^{-}$onto ACWNS were evaluated using pseudo-first-order, pseudo-second-order, and Elovich adsorption kinetics models. The pseudo-first-order equation is given in Eq. (7) (Han et al., 2007).

$$
q_{\mathrm{t}}=q_{\mathrm{e}}\left(1-e^{-k_{1} t}\right)
$$

and Eq. 8 illustrates pseudo-second-order(Ho \& Mckay, 1999):

$$
q_{\mathrm{t}}=\frac{k_{2} q_{\mathrm{e}}^{2} t}{1+k_{2} q_{\mathrm{e}} t}
$$

while Eq. 9 expresses Elovich equation (R. Zhang, Zhang, Zhang, Dou, \& Han, 2014b):

$$
q_{\mathrm{t}}=A+B \ln t
$$

To evaluate the parameters of kinetic models, nonlinear regressive regression was used.The calculated coefficient $\left(R^{2}\right)$ and errors $(S S E)$ can be used to determine a model's adequacy.The obtained kinetic models parameters are exhibited in Table 3 and the fitted curves are also illustreted in Fig. $5 \mathrm{c}$ and d. From Table 3, the Pseudo-second-order model depicted the best fit under the same experimental conditions $\left(R^{2}=0.993, S S E=1.60\right.$ to 3.09) for phosphate and $\left(R^{2}=0.988-0.993, S S E=1.37\right.$ to 2.21$)$ for nitrate and the acquired $q_{e}$ values were near to experimental results. Furthermore, the pseudo-second-order fitted curves were closer to experimental data compared to pseudo-first-order and Elovich kinetic models (Fig. $5 \mathrm{c}$ and d). This predicts that the rate limiting step could be chemisorption or ion exchange (Mpatani et al., 2021). Nonetheless, the $\mathrm{R}^{2}$ values derived from pseudo-first-order and Elovich kinetic models were quite high (Table 3). This depicts that the uptake of both $\mathrm{PO}_{4}{ }^{3-}$ and $\mathrm{NO}_{3}{ }^{-}$could also be predicted by pseudo-first-order and Elovich kinetic models, showing the complexity of these adsorption processes. Since the Elovich model could predict ion-exchange it reveals that $\mathrm{PO}_{4}{ }^{3-}$ and $\mathrm{NO}_{3}{ }^{-}$uptake behaviour on ACWNS could not suggest chemisorption only but also ion-exchange reactions (Zhang et al., 2012; Li et al., 2019)

The intra-particle diffusion (IPD) equation was used to describe the kinetic effects of $\mathrm{PO}_{4}{ }^{3-}$ and $\mathrm{NO}_{3}{ }^{-}$ adsorption onto ACWNS.. Equation 10 illustrates the IPD model (Cao et al., 2014).

$$
q_{\mathrm{t}}=K_{\mathrm{id}} t^{1 / 2}+C
$$


where $K_{\text {id }}$ is the IPD rate constant $\left(\mathrm{g} \mathrm{mg}^{-1} \min ^{-1 / 2}\right), C$ is the constant $\left(\mathrm{mg} \mathrm{g}^{-1}\right)$ that shows the thickness of the boundary layer, i.e., the bigger the value of $C$, the greater the boundary layer effect. Fig. 6 shows a graph of $q_{\mathrm{t}}$ versus $t^{1 / 2}$ for $\mathrm{PO}_{4}{ }^{3-}$ and $\mathrm{NO}_{3}{ }^{-}$adsorption. If a graph of qt against $\mathrm{t}^{1 / 2}$ as seen in Fig. $6 \mathrm{a}$ and $6 \mathrm{~b}$, indicates that the adsorption mechanism had more than two stages. Conversely, IPD is the rate-controlling phase if the line moves through the origin. Alternatively, the IPD may not be the sole rate-limiting step. The adsorption mechanism went through three phases, as seen in Fig. 6 a and b. External surface adsorption was the first step, driven by boundary layer diffusion; the second stage was IPD, followed by final equilibrium adsorption (Aryee et al., 2021;Pan et al., 2017). The second or third phase, which represented the adsorption stage, was linear and constant, with IPD dominanting (Pan et al., 2017; Aryee et al., 2021). The values of $K_{\mathrm{t}}$ and $C$ are listed in Table 3. The values of $C$ were not to equal zero. This means that surface adsorption and IPD may be expected to regulate the adsorption mechanism in both cases (Aryee et al., 2020). Consequently, it indicates that external mass transfer followed by IPD mass transfer could regulate $\mathrm{PO}_{4}{ }^{3-}$ and $\mathrm{NO}_{3}{ }^{-}$adsorption onto ACWNS. Table 3 shows that $K_{\mathrm{t} 1}$ is larger than $K_{\mathrm{t} 2}, C_{1}$ is lower than $C_{2}$, and the $R^{2}$ value in the first adsorption stage is higher than the $R^{2}$ value in the second process in both situations. As a result, IPD could be able to forecast the kinetic mechanism at different stages (Aryee et al., 2021; Pan et al., 2017) .

\subsubsection{Adsorption of $\mathrm{PO}_{4}{ }^{3-}$ and $\mathrm{NO}_{3}{ }^{-}$in binary systems}

The uptake in a binary method was conducted and the results obtained are presented in Fig. 6. Noticeably, an inconsequential decrease in the uptake of phosphate (from 21.15 to $15.2 \mathrm{mg} \mathrm{g}^{-1}$; reduction of $14.4 \%$ ) and nitrate (from 15.2 to $12.09 \mathrm{mg} \mathrm{g}^{-1}$; reduction of $10.4 \%$ ) onto ACWNS in the binary solution system was witnessed. This may be attributed to the presence of a variety of active sites on ACWNS that exhibit a degree of anionspecificity.The outcomes infer that ACWNS to some extent exhibited higher affinity towards the adsorption of both ions. Therefore, ACWNS presents itself as a prospective adsorbent for the uptake of $\mathrm{PO}_{4}{ }^{3-}$ and $\mathrm{NO}_{3}{ }^{-}$from wastewater in a binary system simultaneously prior to its release into aquatic systems.

\subsubsection{Application to the treatment of real water samples}

From this study, it was established that the initial level of $\mathrm{PO}_{4}{ }^{3-}$ in the tap and lake water was 0.09 and 0.108 $\mathrm{mg} \mathrm{L}{ }^{-1}$, while $\mathrm{NO}_{3}^{-}$levels in the tap and lake water were 1.04 and $2.47 \mathrm{mg} \mathrm{L}^{-1}$ respectively, which are lower than the permissible limits reported by World Health organisation, (2011). The adsorption efficacy of ACWNS for $\mathrm{PO}_{4}{ }^{3-}$ and $\mathrm{NO}_{3}{ }^{-}$adsorption was found to be greater than $90 \%$ in all environmental media in the sorption experiments. From this data, it was evident that ACWNS exhibits great prospects as an adsorbent for the practical remediation processes. Table 6 presents the statistical analysis for the recovery of $\mathrm{PO}_{4}{ }^{3-}$ and $\mathrm{NO}_{3}{ }^{-}$from the real water samples.

\subsubsection{Reusability studies}

To test the usability of the exhausted adsorbent, recovery and reuse studies were undertaken. This process helps to establish the economical, efficient practicability of the prepared adsorbent (ACWNS) with regard to adsorption

343 (Kani et al., 2021; Bhatti et al., 2020; Gu et al., 2019; Zhou et al., 2015) Again, the process might help to 344 comprehend chemical reactions associated with the uptake of the pollutants. This study was done with $0.1 \mathrm{~mol} \mathrm{~L}^{-1}$ of $\mathrm{NaOH}, 0.1 \mathrm{~mol} \mathrm{~L}^{-1} \mathrm{HCl}$ and $0.1 \mathrm{~mol} \mathrm{~L}-1 \mathrm{NaOH}-\mathrm{NaCl}$ as an eluting agent for desorbing both phosphate loaded and 
desorption efficiency for both $\mathrm{PO}_{4}{ }^{3-}$ and $\mathrm{NO}_{3}{ }^{-}$( $\mathrm{NaOH}-\mathrm{NaCl}$ was $94 \%, \mathrm{NaOH} 88 \%$, and $\mathrm{HCl} 70 \%$ for $\mathrm{PO}_{4}{ }^{3-}$, and $\mathrm{NaOH}-\mathrm{NaCl}$ was $89 \%, \mathrm{NaOH} 82 \%$, and $\mathrm{HCl} 67 \%$ ).The desorption efficiency remains fairly constant at about $94 \%$ for $\mathrm{PO}_{4}{ }^{3-}$ and 89, 78 and $73 \%$ for $\mathrm{NO}_{3}{ }^{-}$. The removal effectiveness of ACWNS was not influenced greatly by the desorption process as the regeneration performance of ACWNS towards $\mathrm{PO}_{4}{ }^{3-}$ was 90,87 and $82 \%$ and 87,83 and $77 \%$ for $\mathrm{NO}_{3}{ }^{-}$after three successive cycles. As exhibited in Fig. 3 a and b, the uptake capacity of ACWNS was observed to be very low in an alkaline medium, indicating that, the occurrence of excess $\mathrm{OH}^{-}$and $\mathrm{Cl}^{-}$in solution disrupts the interactions that occur between the adsorbate and the binding sites on ACWNS resulting in a higher desorption rate of both phosphate and nitrate. This could be elucidated based on the principle of ion exchange between the negative ions in the solution and the nutrients $\left(\mathrm{PO}_{4}{ }^{3-}\right.$ and $\mathrm{NO}_{3}{ }^{-}$) on the surface of ACWNS (Gu et al., 2019). This state causes adsorbates to be released into solution as well as the creation of many active sites for further adsorption phases. The end usage of the adsorbent is critical, since improper disposal will result in environmental degradation, which has a knock-on impact on the whole ecosystem. It is necessary to dispose of this adsorbent in the dirt, which has a number of advantages. ACWNS's mineral composition (i.e. N, C, and O) has been shown to foster soil and plant growth, thus aiding in environmental management and biodiversity.

\subsection{Thermodynamic Studies}

To further grasp the effect of temperature on the absorption process of $\mathrm{PO}_{4}{ }^{3-}$ and $\mathrm{NO}_{3}{ }^{-}$onto ACWNS, thermodynamic parameters such as Gibbs free energy $\left(\Delta G^{\circ}\right)$ (Eq. 12), enthalpy shift $\left(\Delta H^{\circ}\right)$ (Eq. 13), and entropy change $\left(\Delta S^{\circ}\right)($ Eq. 13) is calculated using the following equations (Cao et al., 2014).

$$
K_{c}=q_{\mathrm{e}} / C_{\mathrm{e}}
$$

$\Delta G^{\mathrm{o}}=-R T \ln K_{\mathrm{c}}$

$$
\Delta G^{\mathrm{o}}=\Delta H^{\mathrm{o}}-T \Delta S^{\mathrm{o}}
$$

where $q_{\mathrm{e}}\left(\mathrm{mg} \mathrm{g}^{-1}\right)$ is the equilibrium loading capacity, $C_{\mathrm{e}}\left(\mathrm{mg} \mathrm{L}^{-1}\right)$ is the equilibrium concentration of the pollutant solution. $K_{\mathrm{c}}$ (Eq. 11) $\left(\mathrm{L} \mathrm{mg}^{-1}\right)$ is the distribution coefficient obtained from the lowest experimental $\mathrm{PO}_{4}{ }^{3-}$ and $\mathrm{NO}_{3}{ }^{-}$ concentrations. $T(\mathrm{~K})$ is the absolute temperature in Kelvin; $R\left(8.314 \mathrm{~J} \mathrm{~mol}^{-1} \mathrm{~K}^{-1}\right)$ is the ideal gas constant. The values of $\Delta H^{\circ}$ is enthalpy and $\Delta S^{\circ}$ is degree of randomness (Eq. 13). As illustrated in Table 4 , the negative values of $\Delta G^{\circ}$ for $\mathrm{PO}_{4}{ }^{3-a n d} \mathrm{NO}_{3}{ }^{-}$at all temperatures proved the spontaneity and irreversibility of the uptake processes (Mpatani et al., 2021 ;Aryee et al., 2021) As temperature increased, the absolute values of $\Delta \mathrm{G}^{\circ}$ decreased, implying that adsorption of contaminants into ACWNS was more beneficial at lower temperatures. Besides, lower values for $\Delta G^{\circ}$, suggest that physical process might chiefly control the adsorption process (Subbaiah and Kim, 2016; Kumar et al., 2014). Phosphate uptake has a lower $\Delta G^{\circ}$ than nitrate, which is consistent with studies reported by Wang et al., (2018), indicating that $\mathrm{PO}_{4}{ }^{3-}$ is easier to be removed. Moreover, the negative values of $\Delta H^{\circ}$ for both $\mathrm{PO}_{4}{ }^{3-}(-9.46 \mathrm{~kJ}$ $\left.\mathrm{mol}^{-1}\right)$ and $\mathrm{NO}_{3}^{-}\left(-17.8 \mathrm{~kJ} \mathrm{~mol}^{-1}\right)$ illustrate an exothermic uptake process; therefore high temperatures do not promote their adsorption. It has been detailed that for uptake to be controlled by physisorption, $\Delta H^{\circ}$ must be less than $40 \mathrm{~kJ} \mathrm{~mol}^{-1}$. (Aryee et al., 2021; Kumar et al., 2014). Consequently, the adsorption mechanism of $\mathrm{PO}_{4}{ }^{3-}$ and $\mathrm{NO}_{3}{ }^{-}$onto ACWNS is physisorption based on the enthalpy change values recorded as presented in Table 4. Furthermore, the entropy of the aqueous interface during the uptake process increased, depicting a positive $\Delta S^{\circ}$ values (Han et al., 2009). 


\subsection{Adsorption mechanisms}

To further understand the reaction mechanism involved in the adsorption of nutrients onto ACWNS, the XPS technique was employed. The analysis revealed the elemental compostion of WNS, ACWNS before and after the uptake of the $\mathrm{PO}_{4}{ }^{3-}$ and $\mathrm{NO}_{3}{ }^{-}$. Fig. 8 a, b, c and d illustrate the XPS wide spectrum results. It was seen from Fig. 7 a that the elements $\mathrm{C}$ and $\mathrm{O}$ were present in the adsorbent before modification, which signifies that they are inherent in agricultural based adsorbent. The emergence of $\mathrm{N}$ 1s on the adsorbent as shown in Fig. 8 b confirmed successful modification and the appearance of P2p confirms the adsorption of phosphate ions onto ACWNA (Fig. 7 d). A narrow scan of the $\mathrm{N} 1 \mathrm{~s}$ spectrum of ACWNS showed two peaks at $398.5 \mathrm{eV}$ and $401.3 \mathrm{eV}$ which might be attributed to $\mathrm{C}-\mathrm{N}$ and quaternary nitrogen respectively (Luo et al., 2019). After the uptake of nitrate, a bond linked to quaternary nitrogen at $401.3 \mathrm{eV}$ shifted slightly and a new peak emerged which could be credited to N-O at $404.01 \mathrm{eV}$. The nitrogen composition was found to have increased from $12.97 \%$ to $14.45 \%$, affirming the adsorption of nitrate onto ACWNS. Again, the resolution of the O1s spectrum of ACWNS before (Fig. $7 \mathrm{~g}$ ) and after (Fig. $7 \mathrm{~h}$ ) adsorption of nitrate gave four peaks. The binding energies of the peaks resulting from ACWNS are $532.12 \mathrm{eV}$ for $\mathrm{C}-\mathrm{O}-\mathrm{C}, 531.18 \mathrm{eV}$ for $\mathrm{C}=\mathrm{O}, 530.53 \mathrm{eV}$ for $\mathrm{C}-\mathrm{O}-\mathrm{H}$, and $533.07 \mathrm{eV}$ for $-\mathrm{O}-\mathrm{H}$ ( $\mathrm{Li}$ and Bai, 2005). There were no significant alteration in the binding positions of the $\mathrm{O} 1 \mathrm{~s}$ peaks after adsorption (Fig. $8 \mathrm{~h}$ ). However, the oxygen content on ACWNS increased marginally from 18.15 to $24 \%$. This could be assigned to the uptake of nitrate ions. Furthermore, after the uptake of phosphate onto ACWNS, the $\mathrm{N} \mathrm{1s} \mathrm{spectrum} \mathrm{showed} \mathrm{two} \mathrm{peaks} \mathrm{at}$ $397.96 \mathrm{eV}$ emanating from $\mathrm{C}-\mathrm{N} / \mathrm{N}-\mathrm{H}$ and $400.73 \mathrm{eV}$ match up to quaternary nitrogen (Fig.8 i) and the analysis also revealed a reduction in the nitrogen content from $12.97 \%$ to $9.85 \%$ showing its involvement in the adsorption process. Aditionally, $\mathrm{O} 1 \mathrm{~s}$ spectrum peaks after the uptake of phosphate showed five peaks corresponding to $-\mathrm{OH}$ at $533.56 \mathrm{eV}, \mathrm{C}-\mathrm{O}-\mathrm{C}$ at $532.65 \mathrm{eV}, \mathrm{C}=\mathrm{O}$ at $531.63 \mathrm{eV}, \mathrm{C}-\mathrm{O}-\mathrm{H}$ at $530.70 \mathrm{eV}$ and $529.46 \mathrm{eV}$ attributable to $\mathrm{O}=\mathrm{C}-$ $\mathrm{OH} / \mathrm{O}-\mathrm{P}$. After the adsorption, oxygen content increased from 18.15 to $25 \%$, which could be credited to the adsorption process. Fig. $8 \mathrm{k}$ shows the P2p spectrum of ACWNS- $\mathrm{PO}_{4}{ }^{3-}$ confirming the adsorption of phosphate with total phosphrous content of $1.44 \%$.

\section{Conclusion}

In this studies, walnut shell is functionalized (ACWNS) through grafting quaternary amine groups via crosslink reaction and utilized as an adsorbent for effective uptake of phosphate and nitrate from aqueous media in a single-component and binary system. The efficiency of ACWNS was considerably influenced by $\mathrm{pH}$, concentration, dosage, time and temperature. The surface characteristics of the adsorbent were assessed using analytical techniques which confirmed its involvement in the uptake of the nutrients $\left(\mathrm{PO}_{4}{ }^{3-}\right.$ and $\left.\mathrm{NO}_{3}{ }^{-}\right)$. The results also showed that ACWNS had an enhanced uptake capacity for phosphate than nitrate, which could be linked to a bigger atomic number and greater valence for phosphate. The phosphate and nitrate adsorption process was spontaneous and exothermic. Pseudo-second-order kinetics better fit the adsorption of all nutrients, while Freundlich and Langmuir's equations best fit the adsorption of phosphate and nitrate, respectively. Moreover, the results obtained from isotherm, kinetic and thermodynamic studies revealed that both chemical and physical processes occasioned the uptake process which explained the complex nature of $\mathrm{PO}_{4}{ }^{3-}$ and $\mathrm{NO}_{3}{ }^{-}$uptake onto ACWNS. Further studies in a binary system confirmed that the prepared adsorbent exhibited a higher affinity towards the adsorption of both ions 
421 and could serve as a plausible material for the removal of both ions simultaneously from aqueous media. Again, the

422 efficiency of ACWNS was affirmed when applied to the practical remediation of wastewater. This study presents a

423 simplistic method for the construction of a new adsorbent which is highly effective, inexpensive, eco-friendly,

424 reusable and most promising for use to uptake $\mathrm{PO}_{4}{ }^{3-}$ and $\mathrm{NO}_{3}{ }^{-}$across a wide $\mathrm{pH}$ range, which makes it

425 advantageous for not altering the $\mathrm{pH}$ of contaminated solutions in a real sample before treatment. Therefore,

426 ACWNS has a huge prospect of being used as a valuable adsorbent to be applied practically to treat wastewater.

427 Authors' contribution

428 1). Evans Dovi (evansdovy@gmail.com): Conceptualization; Methodology; Formal analysis; Investigation; Writing 429 original draft; Visualization.

430 2). Aaron Albert Aryee (a.niiayi@yahoo.com): Software, writing-review and editing, formal analysis

431 3). Jianjun Li (lijianjun@zzu.edu.cn) Visualization; Supervision; funding acquisition

432 4). Lingbo Qu (qulingbo@zzu.edu.cn): Resources, funding acquisition.

433 5). Zhaohui Li (zhaohui.li@zzu.edu.cn): Visualization; Supervision; funding acquisition.

434 6). Runping Han (rphan67@zzu.edu.cn): Conceptualization; Resources; Project administration; Writing-review and editing, Visualization; Supervision; Funding acquisition

\section{Declaration of Competing Interest}

The authors declare that they have no known competing financial interests or personal relationships that could have appeared to influence the work reported in this paper.

Acknowledgement

This work was supported in part by the National Natural Science Foundation of China (21205108, 21974125), the Foundation for University Key Teacher by Henan Province (2017GGJS007), and the Key Scientific Research

442 Project in Universities of Henan Province (19A150048).

Availability of data and material

444 The dataset generated and analysed during this study could be obtained from the corresponding author on reasonable 445 request

446 Ethics approval

447 Not Applicable

448 Consent to participate

449 Not Applicable

450 Consent for publication

$451 \quad$ Not Applicable

452 References

453 Aryee, A A, Dovi, E, Shi, X, Han, R, Li, Z, Qu, L (2021). Zirconium and iminodiacetic acid modified magnetic peanut husk as a novel adsorbent for the sequestration of phosphates from solution : Characterization , equilibrium and kinetic study. Colloid. Surface. A 615, 126260.. https://doi.org/10.1016/j.colsurfa.2021.126260 
ed peanut husk as a novel adsorbent for the uptake of $\mathrm{Cu}$ ( II ) and $\mathrm{Pb}$ ( II ) in aqueous solution :

Characterization, equilibrium and kinetic study . Environ. Pollut., 268, 115729. https://doi.org/10.1016/j.envpol.2020.115729

Aryee, A A, Mpatani, F M, Kani, A N, Dovi, E, Han, R (2020). Iminodiacetic acid functionalized magnetic peanut husk for the removal of methylene blue from solution : characterization and equilibrium studies. J. Clean. Prod. 268 , 122191. https://doi.org/10.1016/j.jclepro.2020.122191

Banu, HT, Meenakshi, S (2017). One pot synthesis of chitosan grafted quaternized resin for the removal of nitrate and phosphate from aqueous solution. 104 1517-1527. https://doi.org/10.1016/j.ijbiomac.2017.03.043

Bhardwaj, D, Sharma, M, Sharma, P, Tomar, R (2012). Synthesis and surfactant modification of clinoptilolite and montmorillonite for the removal of nitrate and preparation of slow release nitrogen fertilizer. J. Hazard Mater., 227-228, 292-300. https://doi.org/10.1016/j.jhazmat.2012.05.058

Bhatti, H N, Safa, Y, Yakout, S M, Shair, O. H, Iqbal, M, Nazir, A (2020). Ef fi cient removal of dyes using carboxymethyl cellulose / alginate / polyvinyl alcohol / rice husk composite : Adsorption / desorption , kinetics and recycling studies. Int. J. Biol.Macromol, 150, 861-870. https://doi.org/10.1016/j.ijbiomac.2020.02.093

Cao, J S, Lin, J X, Fang, F, Zhang, M T, Hu, Z R (2014). A new absorbent by modifying walnut shell for the removal of anionic dye: Kinetic and thermodynamic studies. Bioresour. Technol., 163, 199-205. https://doi.org/10.1016/j.biortech.2014.04.046

Cheng, S, Zhang, L, Xia, H, Peng, J (2017). Characterization and adsorption properties of La and Fe modified activated carbon for dye wastewater treatment. Green Process Synth. 6(5) 487-498. https://doi.org/10.1515/gps-2016-0120

Dovi, E., Kani, A. N., Aryee, A. A., Jie, M., Li, J., Li, Z., \& Qu, L. (2021). Decontamination of bisphenol A and Congo red dye from solution by using CTAB functionalised walnut shell. Environ. Sci. Pollut. Res. in press. https://doi.org/10.1007/s11356-021-12550-4

Eberhardt, T L, Min, S, Han, J S (2006). Phosphate removal by refined aspen wood fiber treated with carboxymethyl cellulose and ferrous chloride. Bioresour. Technol. 97 2371-2376. https://doi.org/10.1016/j.biortech.2005.10.040

Fan, C, Zhang, Y (2018). Adsorption isotherms, kinetics and thermodynamics of nitrate and phosphate in binary systems on a novel adsorbent derived from corn stalks. J. Geochem. Explor. 188 95-100. https://doi.org/10.1016/j.gexplo.2018.01.020

Foroughi-Dahr, M, Abolghasemi, H, Esmaieli, M, Nazari, G, \& Rasem, B (2015) Experimental study on the adsorptive behavior of Congo red in cationic surfactant-modified tea waste. Process Saf. Environ. Prot. 95, 226-236. https://doi.org/10.1016/j.psep.2015.03.005

Ganesan, P, Kamaraj, R, Vasudevan, S (2013). Application of isotherm, kinetic and thermodynamic models for the adsorption of nitrate ions on graphene from aqueous solution. J. Taiwan Inst. Chem. E. 44 (2013) $808-814$. https://doi.org/10.1016/j.jtice.2013.01.029 
Gu, Y, Yang, M, Wang, W, Han, R (2019). Phosphate Adsorption from Solution by Zirconium-Loaded Carbon Nanotubes in Batch Mode. J. Chem. Eng. Data 64 , 2849-2858

Hamoudi, S, Belkacemi, K (2013). Adsorption of nitrate and phosphate ions from aqueous solutions using organically-functionalized silica materials : Kinetic modeling. Fuel, 110, 107-113. https://doi.org/10.1016/j.fuel.2012.09.066

Hamoudi, S, Saad, R, Belkacemi, K, La, V (2007). Adsorptive Removal of Phosphate and Nitrate Anions from Aqueous Solutions Using Ammonium-Functionalized Mesoporous Silica. Ind. Eng. Chem. Res. 46, 88068812. https://doi.org/10.1021/ie070195k

Han, R, Wang, Y, Zhao, X, Wang, Y, Xie, F (2009). Adsorption of methylene blue by phoenix tree leaf powder in a fixed-bed column : experiments and prediction of breakthrough curves. DES, 245(1-3), 284-297. https://doi.org/10.1016/j.desal.2008.07.013

Han, R, Zou, W, Yu, W, Cheng, S, Wang, Y, Shi, J (2007). Biosorption of methylene blue from aqueous solution by fallen phoenix tree 's leaves. J. Hazard. Mater.141, 156-162. https://doi.org/10.1016/j.jhazmat.2006.06.107

Ho, Y S, Mckay, G (1999). Pseudo-second order model for sorption processes. Process Biochem. 34, 451-465. https://doi.org/10.1016/s0032-9592(98)00112-5

Hu, Y, Han, R (2019). Selective and Efficient Removal of Anionic Dyes from Solution by Zirconium(IV) Hydroxide-Coated Magnetic Materials. J. Chem. Eng. Data, 64(2), 791-799. https://doi.org/10.1021/acs.jced.8b01063

Kalaruban, M, Loganathan, P, Shim, W G, Kandasamy, J, Ngo, H H, Vigneswaran, S (2016). Enhanced removal of nitrate from water using amine-grafted agricultural wastes. Sci. Total Environ., 565, 503-510. https://doi.org/10.1016/j.scitotenv.2016.04.194

Kani, A N, Dovi, E, Aryee, A A, Mpatani, F M, Han, R, Li, Z, Qu, L (2021). Polyethylenimine modified tiger nut residue for removal of Congo red from solution. Desalin. Water Treat. 215 209-221. https://doi.org/10.5004/dwt.2020.25735

Katal, R, Sharifzadeh, M, Taher, H, Esfandian, H (2012). Kinetic , isotherm and thermodynamic study of nitrate adsorption from aqueous solution using modified rice husk. J. Inds. Eng. Chem., 18(1), 295-302. https://doi.org/10.1016/j.jiec.2011.11.035

Kumar, R, Rashid, J, Barakat, M A (2014) Synthesis and characterization of a starch - congo red dye from aqueous solution. RSC Advs. 38334-38340. https://doi.org/10.1039/c4ra05183a

Leah, M, Castro, F A De, Love, M, Abad, B, Angela, D, Sumalinog, G, Luna, G De. (2018). Adsorption of Methylene Blue dye and $\mathrm{Cu}$ ( II ) ions on EDTA-modi fi ed bentonite : Isotherm, kinetic and thermodynamic studies. Sustain. Environ. Res. 28 (5) 197-205. https://doi.org/10.1016/j.serj.2018.04.00

Li, N, Bai, R (2005) A novel amine-shielded surface cross-linking of chitosan hydrogel beads for enhanced metal adsorption performance. Ind. Eng. Chem. Res., 44(17), 6692-6700. https://doi.org/10.1021/ie050145k

Li, S, Qiu, M, Zeng, Z, Xue, W (2019). Effective Modified Walnut Shell Adsorbent: Synthesis and Adsorption 
Behavior for $\mathrm{Pb}^{2+}$ and $\mathrm{Ni}^{2+}$ from Aqueous Solution. Environ. Eng. Sci., 36(11), 1421-1432. https://doi.org/10.1089/ees.2019.0227

Li, Y, Peng, L, Li, W (2020). Adsorption behaviors on trace $\mathrm{Pb}^{2+}$ from water of biochar adsorbents from konjac starch. Ads. Sci. Technol. 38 , 344-356. https://doi.org/10.1177/0263617420948699

Luo, Z, Chen, H, Wu, S, Yang, C, Cheng, J (2019). Enhanced removal of bisphenol A from aqueous solution by aluminum-based MOF/sodium alginate-chitosan composite beads. Chemosphere, 237, 124493. https://doi.org/10.1016/j.chemosphere.2019.124493

Meili, L, Lins, P V S, Costa, M T, Almeida, R L, Abud, A K S, Soletti, J I, Erto, A (2019). Adsorption of methylene blue on agroindustrial wastes: Experimental investigation and phenomenological modelling. Prog. Biophys. Mol. Biol, 141, 60-71. https://doi.org/10.1016/j.pbiomolbio.2018.07.011

Mpatani, F M, Aryee, A A, Kani, AN, Guo, Q, Dovi, E, Qu, L, Li, Z, Han, R. (2020). Uptake of micropollutantbisphenol A, methylene blue and neutral red onto a novel bagasse- b -cyclodextrin polymer by adsorption process. Chemosphere, 259, 127439. https://doi.org/10.1016/j.chemosphere.2020.127439

Mpatani, F M, Han, R, Aryee, A A, Kani, A N, Li, Z, Qu, L (2021). Adsorption performance of modi fi ed agricultural waste materials for removal of emerging micro-contaminant bisphenol A : A comprehensive review. Sci. Total Environ., 780, 146629. https://doi.org/10.1016/j.scitotenv.2021.146629

Onyango, M S, Kuchar, D, Kubota, M, Matsuda, H (2007). Adsorptive Removal of Phosphate Ions from Aqueous Solution Using Synthetic Zeolite. Ind. Eng. Chem. Res. 46, 894-900

World Health Organization, Guidelines for Drinking-Water Quality, ${ }^{\text {th }}$ ed. 2011

Pan, B, Han, F, Nie, G, Wu, B, He, K, Lu, L (2014) New Strategy To Enhance Phosphate Removal from Water by Hydrous Manganese Oxide. Environ. Sci. Technol. 48, 5101-5107. https://doi.org/10.1021/es5004044

Pan, M, Lin, X, Xie, J, Huang, X (2017) Kinetic , equilibrium and thermodynamic studies for modi fi ed palygorskite nano-composites. RSC Adv. 4492-4500. https://doi.org/10.1039/c6ra26802a

Qiao, H, Mei, L, Chen, G, Liu, H, Peng, C, Ke, F, Hou, R (2019) Applied Surface Science Adsorption of nitrate and phosphate from aqueous solution using amine cross-linked tea wastes. Appl. Surf. Sci., 483, 114-122. https://doi.org/10.1016/j.apsusc.2019.03.147

Ren, Z, Xu, X, Wang, X, Gao, B, Yue, Q, Song, W, Wang, H (2016) FTIR, Raman, and XPS analysis during phosphate, nitrate and Cr ( VI ) removal by amine cross-linking biosorbent. J. Colloid Interf. Sci. 468, 313323. https://doi.org/10.1016/j.jcis.2016.01.079

Ribeiro, E M S, Lohbeck, M, Tabarelli, M, Leal, I R (2019) Functional diversity and composition of Caatinga woody flora are negatively impacted by chronic anthropogenic disturbance. J. Ecol. 107 2291-2302. https://doi.org/10.1111/1365-2745.13177

Sowmya, A, Meenakshi, S (2014) A novel quaternized resin with acrylonitrile / divinylbenzene / vinylbenzyl chloride skeleton for the removal of nitrate and phosphate. Chem. Eng. J., 257, 45-55. https://doi.org/10.1016/j.cej.2014.07.015

Subbaiah, M V, Kim, D (2016) Adsorption of methyl orange from aqueous solution by aminated pumpkin seed powder: Kinetics, isotherms, and thermodynamic studies. Ecotoxicol. Environ. Saf. 128 $109-117$. 
https://doi.org/10.1016/j.ecoenv.2016.02.016

Velazquez-jimenez, L H, Arcibar-orozco, J A, Rangel-mendez, J R (2018). Overview of As ( V ) adsorption on Zrfunctionalized activated carbon for aqueous streams remediation. J. Environ. Mgt, 212, 121-130. https://doi.org/10.1016/j.jenvman.2018.01.072

Wada, M, Heux, L, Sugiyama, J. (2004). Polymorphism of Cellulose I Family: Reinvestigation of Cellulose IV I. Biomacromolecules 5, 1385-1391. https://doi.org/10.1021/bm0345357

Wang, R, Xu, Z, Fu, Y, Chen, Y, Pan, Z, Wanga, R, Tan, Z (2018) mechanisms of nitrate and phosphate by modified. RSC Adv., 8, 36468-36476. https://doi.org/10.1039/C8RA06617E

Xu, X, Gao, B, Yue, Q, Li, Q, Wang, Y. (2013) Nitrate adsorption by multiple biomaterial based resins : Application of pilot-scale and lab-scale products. Chem. Eng. J. 234, 397-405. https://doi.org/10.1016/j.cej.2013.08.117

Xu, X, Gao, B, Zhao, Y, Chen, S, Tan, X, Yue, Q, Wang, Y (2012). Nitrate removal from aqueous solution by Arundo donax L . reed based anion exchange resin. J. Hazard. Mater., 203-204(3), 86-92. https://doi.org/10.1016/j.jhazmat.2011.11.094

Xu, X, Gao, Y, Gao, B, Tan, X, Zhao, Y, Yue, Q, Wang, Y (2011). Characteristics of diethylenetriaminecrosslinked cotton stalk / wheat stalk and their biosorption capacities for phosphate. J. Hazard. Mater., 192(3), 1690-1696. https://doi.org/10.1016/j.jhazmat.2011.07.009

Zhan, Y, Lin, J, Zhu, Z (2011) Removal of nitrate from aqueous solution using cetylpyridinium bromide ( CPB ) modified zeolite as adsorbent. J. Hazard. Mater., 186(2-3), 1972-1978. https://doi.org/10.1016/j.jhazmat.2010.12.090

Zhang, R, Zhang, J, Zhang, X, Dou, C, Han, R (2014). Adsorption of Congo red from aqueous solutions using cationic surfactant modified wheat straw in batch mode: Kinetic and equilibrium study. J. Taiwan Inst. Chem. Eng. 45(5), 2578-2583. https://doi.org/10.1016/j.jtice.2014.06.009

Zhang, W, Li, H, Kan, X, Dong, L, Yan, H, Jiang, Z, Cheng, R (2012). Adsorption of anionic dyes from aqueous solutions using chemically modified straw. Bioresour. Technol., 117, 40-47. https://doi.org/10.1016/j.biortech.2012.04.064

Zhang, Z, Moghaddam, L, O’Hara, I M, Doherty, W O S (2011). Congo Red adsorption by ball-milled sugarcane bagasse. Chem. Eng. J., 178, 122-128. https://doi.org/10.1016/j.cej.2011.10.024

Zhao, B, Xiao, W, Shang, Y, Zhu, H, Han, R (2017). Adsorption of light green anionic dye using cationic surfactant-modified peanut husk in batch mode. Arab. J. Chem., 10, S3595-S3602. https://doi.org/10.1016/j.arabjc.2014.03.010

Zhao, H, Yu, Q, Li, M, Sun, S (2020). Preparation and water vapor adsorption of "green" walnut-shell activated carbon by $\mathrm{CO} 2$ physical activation. Ads. Sci. Technol., 38(1-2), 60-76. https://doi.org/10.1177/0263617419900849

Zhao, J, Liang, G, Zhang, X, Cai, X, Li, R, Xie, X, Wang, Z (2019) Coating magnetic biochar with humic acid for high ef fi cient removal of fluoroquinolone antibiotics in water. Sci. Total Environ., 688, 1205-1215. https://doi.org/10.1016/j.scitotenv.2019.06.287 
606

607

608

609

610

611

612

613
Zhou, T, Lu, W, Liu, L, Zhu, H, Jiao, Y, Zhang, S, Han, R (2015) Effective adsorption of light green anionic dye from solution by CPB modified peanut in column mode. J. Mol. Liqs, 211, 909-914. https://doi.org/10.1016/j.molliq.2015.08.018

Zhu, H Y, Fu, Y Q, Jiang, R, Jiang, J H, Xiao, L, Zeng, G M, Wang, Y (2011) Adsorption removal of congo red onto magnetic cellulose/Fe3O4/activated carbon composite: Equilibrium, kinetic and thermodynamic studies.

Chem. Eng. J., 173(2), 494-502. https://doi.org/10.1016/j.cej.2011.08.020 
615 Fig. 1. Synthesis process of ACWNS.

616 Fig. 2. SEM images of (a) pristine WNS and (b) ACWNS; (c) FTIR spectra of WNS, ACWNS and ACWNS-PO $4^{3-}$, $617 \quad \mathrm{ACWNS}-\mathrm{NO}_{3}{ }^{-}$and (d) XRD patterns of ACWNS and WNS.

618 Fig. 3. Influence of $\mathrm{pH}$ on adsorption of $\mathrm{PO}_{4}{ }^{3-}$ (a), $\mathrm{NO}_{3}{ }^{-}$(b); Point of zero charge of WNS and ACWNS (c).

619 Fig. 4. Influence of adsorbent dose on adsorption of $\mathrm{PO}_{4}{ }^{3-}$ (a) and $\mathrm{NO}_{3}{ }^{-}$(b); Influence of salt concentration on $\mathrm{PO}_{4}{ }^{3-}$ (c) and $\mathrm{NO}_{3}{ }^{-}$(d) adsorption by ACWNS $\left(C_{0}=30 \mathrm{mg} \mathrm{L}^{-1}, T=303 \mathrm{~K}, t=1 \mathrm{~h}\right)$.

621 Fig. 5. Adsorption isotherms and fitted curves of $\mathrm{PO}_{4}{ }^{3-}$ (a) and $\mathrm{NO}_{3}{ }^{-}$(b); Contact time and kinetics modeling of $\mathrm{PO}_{4}{ }^{3-}$ (c) and $\mathrm{NO}_{3}{ }^{-}$(d) adsorption onto ACWNS.

623 Fig. 6. Intra-particle diffusion plot for $\mathrm{PO}_{4}{ }^{3-}$ (a) and $\mathrm{NO}_{3}{ }^{-}$(b) adsorption onto ACWNS

624 Fig. 7. Adsorption capacity of ACWNS for $\mathrm{PO}_{4}{ }^{3-}$ and $\mathrm{NO}_{3}{ }^{-}$in single and binary systems $(1: 1$ initial concentration, $30 \mathrm{mg} \mathrm{L}^{-1}, T=303 \mathrm{~K}, t=1 \mathrm{~h}$, dose $=1.0 \mathrm{mg} \mathrm{L}^{-1}$ ).

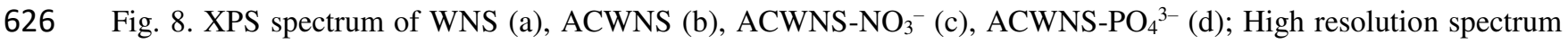
of N1s of ACWNS (e) before and (f) after $\mathrm{NO}_{3}{ }^{-}$adsorption; O1s spectrum of ACWNS (g) before and (h) after $\mathrm{NO}_{3}{ }^{-}$adsorption; N1s spectrum of ACWNS (i) after adsorption of $\mathrm{PO}_{4}{ }^{3-}$; (j) O1s spectrum of ACWNS- $\mathrm{NO}_{3}{ }^{-}$.

629 Fig. 9. Proposed schematic mechanism of $\mathrm{PO}_{4}{ }^{3-}$ and $\mathrm{NO}_{3}{ }^{-}$adsorption onto ACWNS.

\section{Captions of Tables}

631 Table 1 Parameters of adsorption isotherms for $\mathrm{PO}_{4}{ }^{3-}$ and $\mathrm{NO}_{3}{ }^{-}$adsorbed onto ACWNS at varied temperatures

632 Table 2 Comparison of maximum adsorption capacities for uptake of $\mathrm{PO}_{4}{ }^{3-}$ and $\mathrm{NO}_{3}{ }^{-}$using different adsorbents

633 Table 3 Parameters of Kinetic models for $\mathrm{PO}_{4}{ }^{3-}$ and $\mathrm{NO}_{3}{ }^{-}$adsorption onto ACWNS

634 Table 4 Thermodynamic parameters for phosphate and nitrate adsorption on ACWNS

635 Table 5 Statistical analysis for recovery of $\mathrm{PO}_{4}{ }^{3-}$ and $\mathrm{NO}_{3}{ }^{-}$from the real water samples 


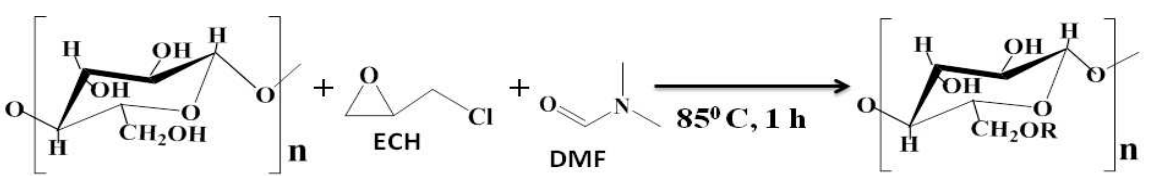

Cellulose in WNS

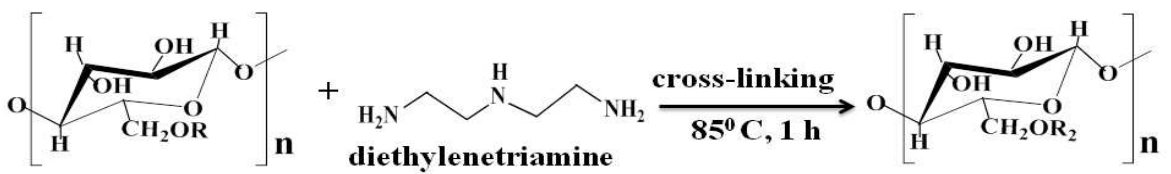

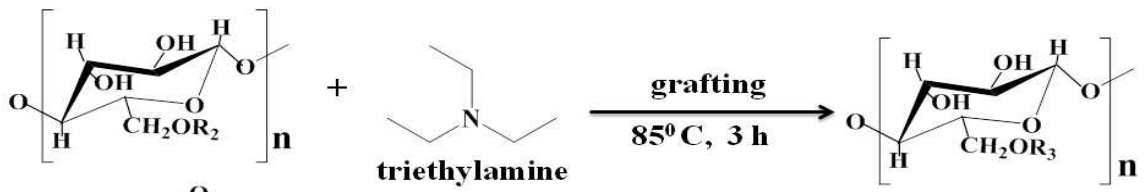

R: $-\mathrm{CH}_{2} \mathrm{CHCH}-\mathrm{CH}_{2}$

$\mathrm{R}_{2}$ :- $\mathrm{CH}_{2} \mathrm{CHCH}_{2}\left(\mathrm{NHCH}_{2} \mathrm{CH}_{2}\right)_{2} \mathrm{NH}_{2} \quad \mathrm{R}_{3}:-\mathrm{CH}_{2} \mathrm{CHCH}_{2}\left(\mathrm{NHCH}_{2} \mathrm{CH}_{2}\right)_{2} \stackrel{+}{\mathrm{N}}\left(\mathrm{C}_{2} \mathrm{H}_{5}\right)_{3}$

Fig. 1. Synthesis process of ACWNS.
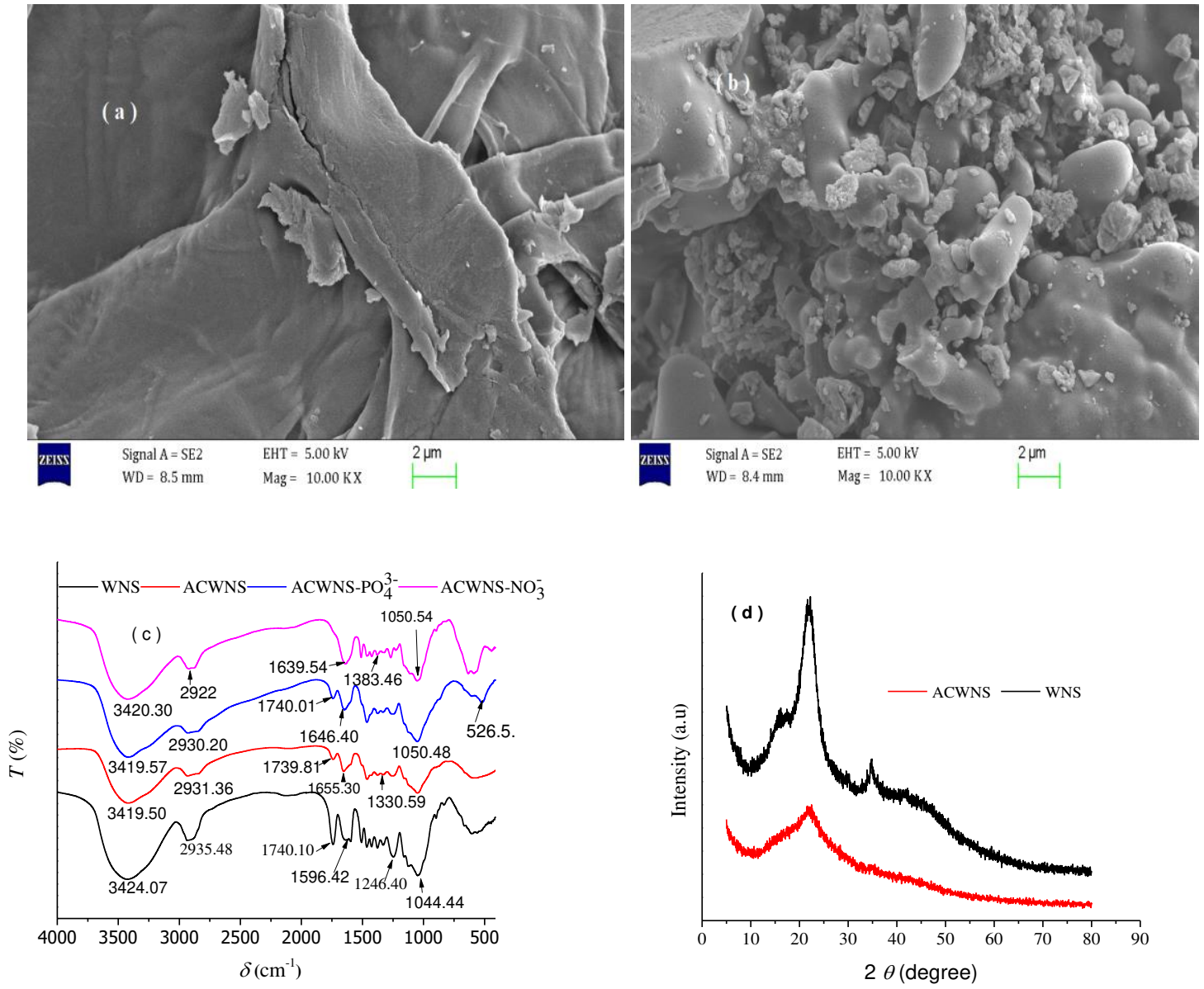

Fig. 2. SEM images of (a) pristine WNS and (b) ACWNS; (c) FTIR spectra of WNS, ACWNS and ACWNS-PO ${ }_{4}^{3-}$,

$642 \quad \mathrm{ACWNS}-\mathrm{NO}_{3}{ }^{-}$and (d) XRD patterns of ACWNS and WNS. 

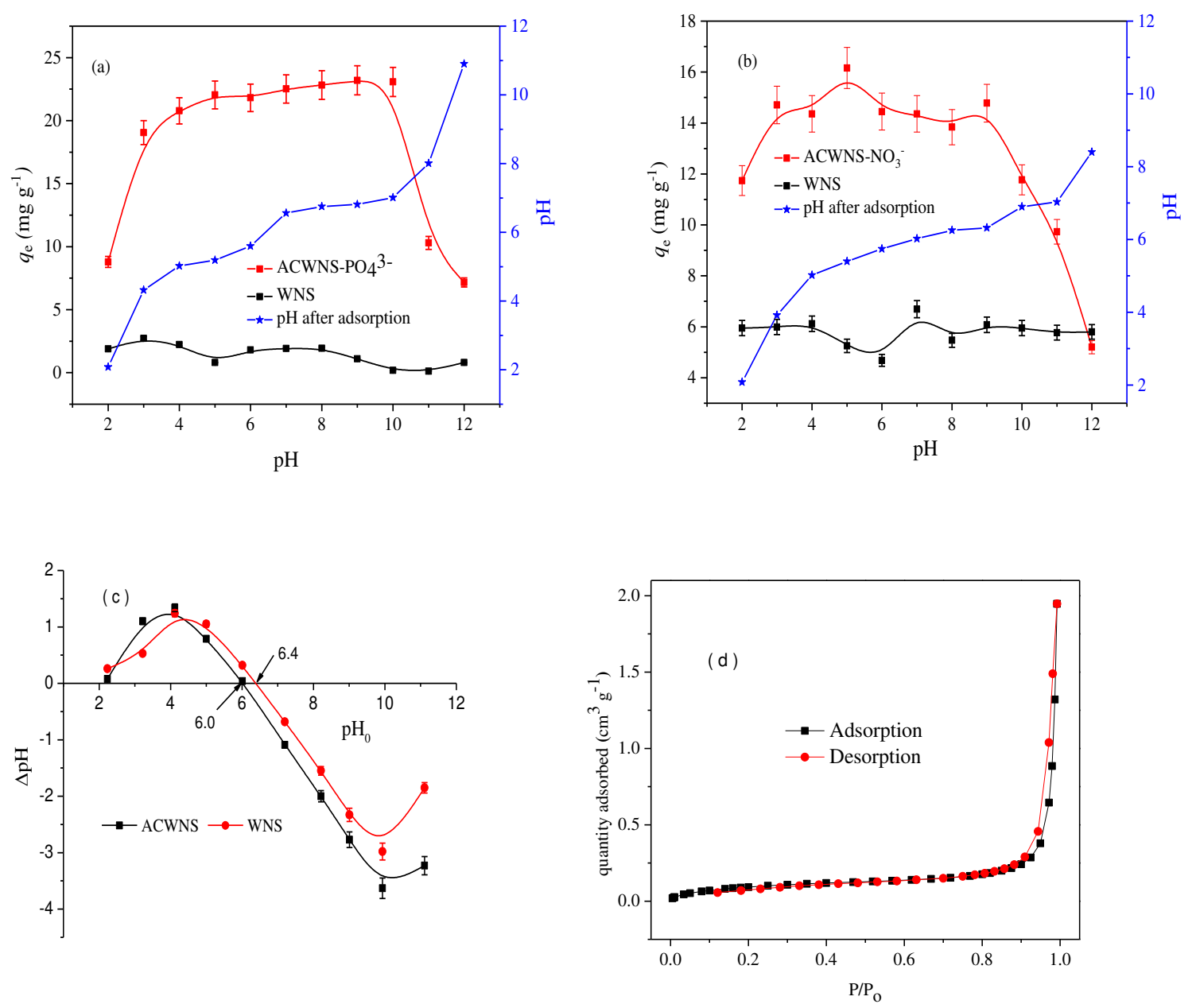

644

645 Fig. 3. Influence of $\mathrm{pH}$ on adsorption of $\mathrm{PO}_{4}{ }^{3-}$ (a), $\mathrm{NO}_{3}{ }^{-}$(b); Point of zero charge of WNS and ACWNS (c);Plot of $646 \mathrm{~N}_{2}$ adsorption/desorption isotherm of ACWNS (d).
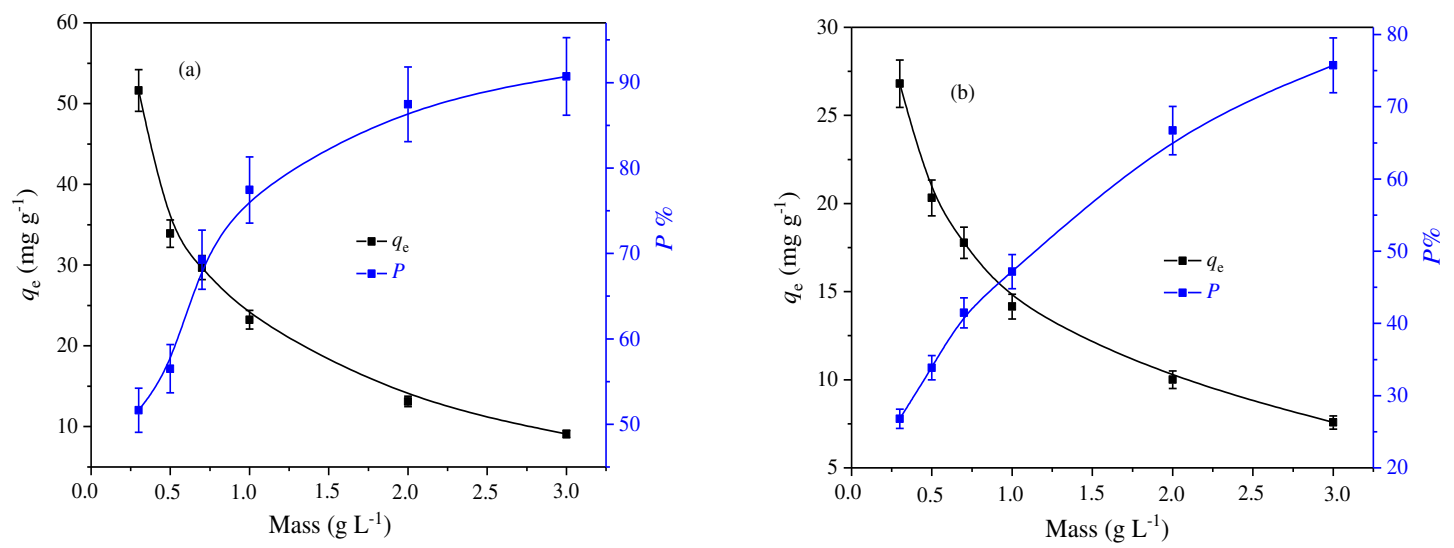

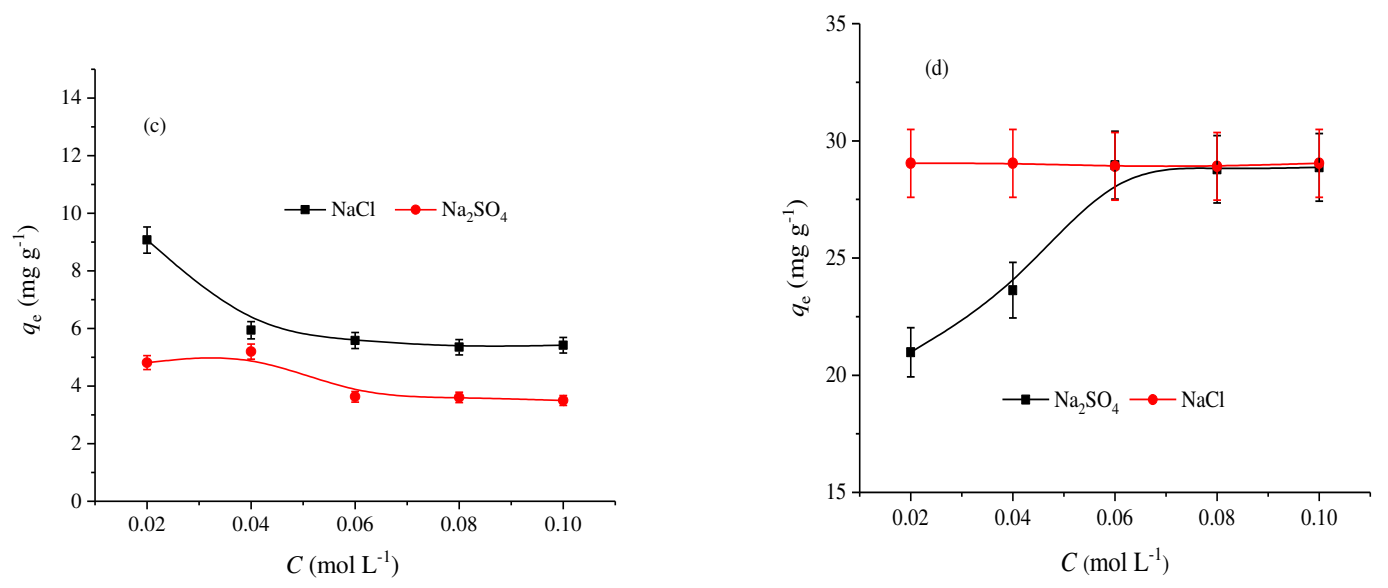

649 Fig. 4. Influence of adsorbent dose on adsorption of $\mathrm{PO}_{4}{ }^{3-}$ (a) and $\mathrm{NO}_{3}{ }^{-}$(b); Influence of salt concentration on $\mathrm{PO}_{4}{ }^{3-}$ 650 (c) and $\mathrm{NO}_{3}{ }^{-}$(d) adsorption by ACWNS $\left(C_{0}=30 \mathrm{mg} \mathrm{L}^{-1}, T=303 \mathrm{~K}, t=1 \mathrm{~h}\right)$.

651 

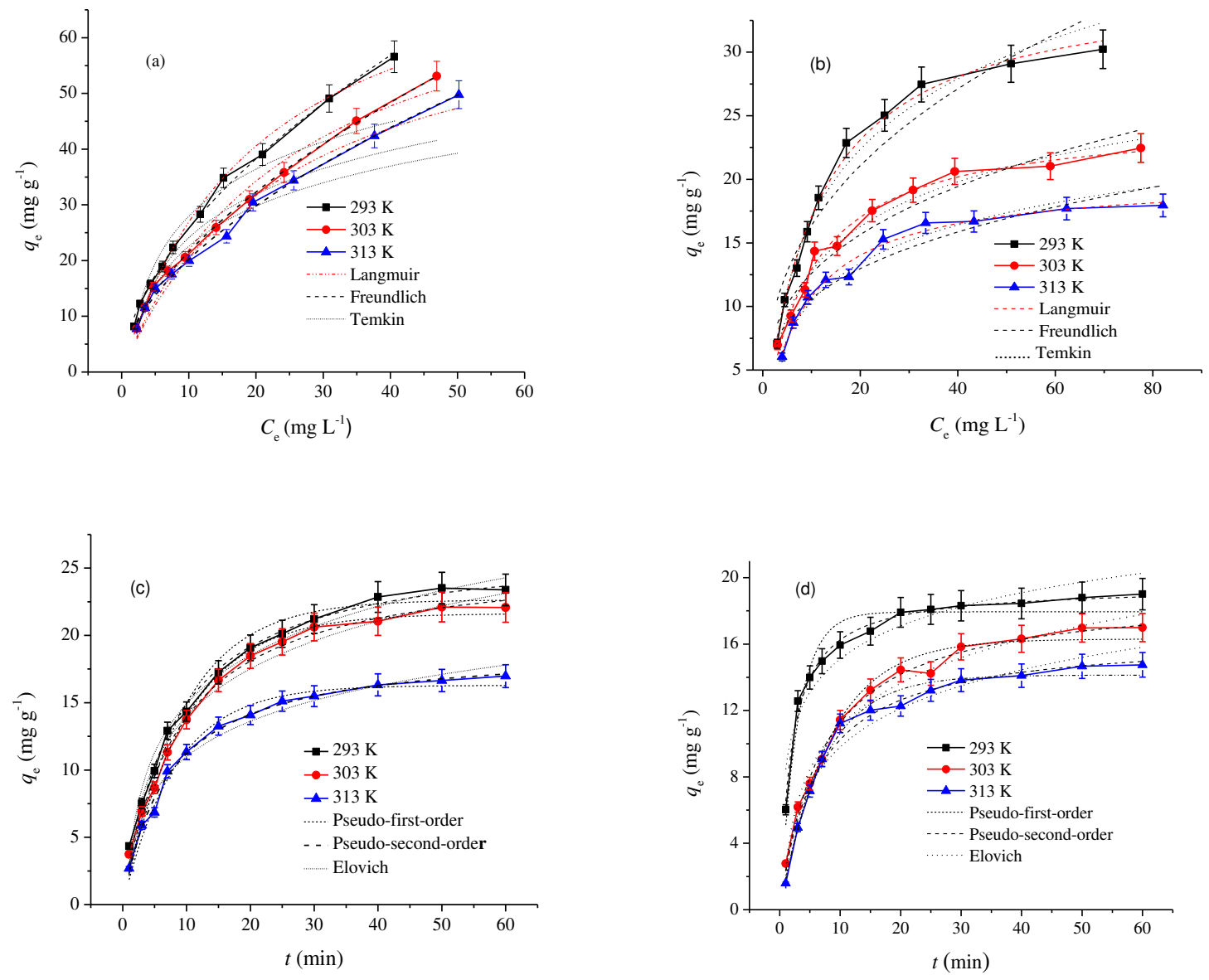

653

654

655

656

657 658
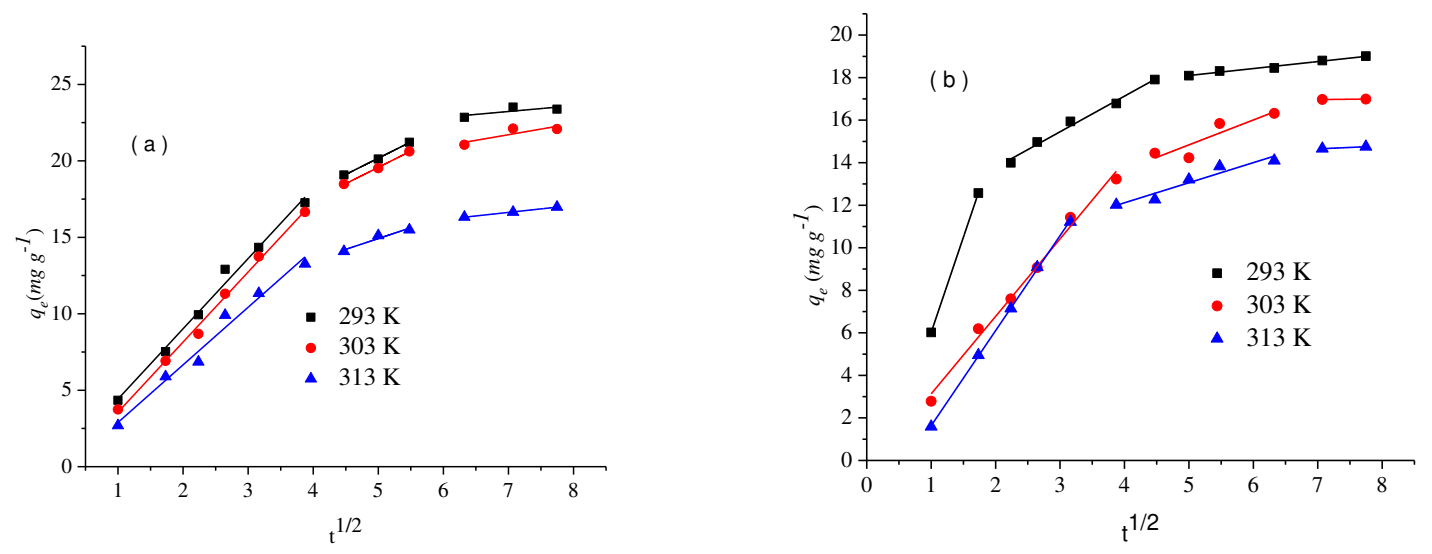

Fig. 6. Intra-particle diffusion plot for $\mathrm{PO}_{4}{ }^{3-}$ (a) and $\mathrm{NO}_{3}{ }^{-}$(b) adsorption onto ACWNS 


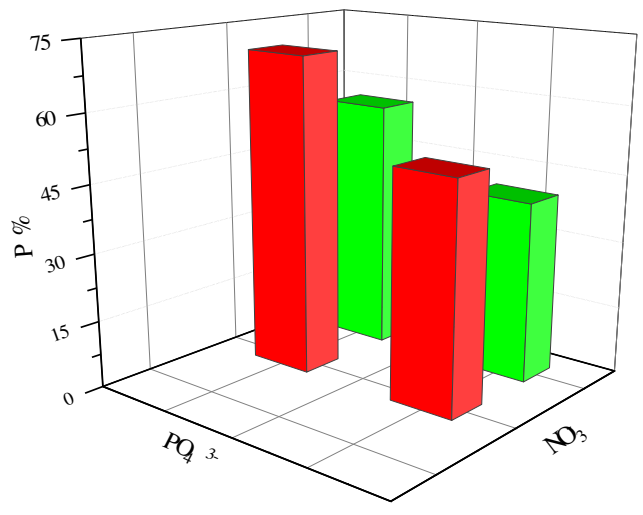

659

660 Fig. 7. Adsorption capacity of ACWNS for $\mathrm{PO}_{4}{ }^{3-}$ and $\mathrm{NO}_{3}{ }^{-}$in single and binary systems $(1: 1$ initial concentration, $30 \mathrm{mg} \mathrm{L}^{-1}, T=303 \mathrm{~K}, t=1 \mathrm{~h}$, dose $=1.0 \mathrm{mg} \mathrm{L}^{-1}$ ).
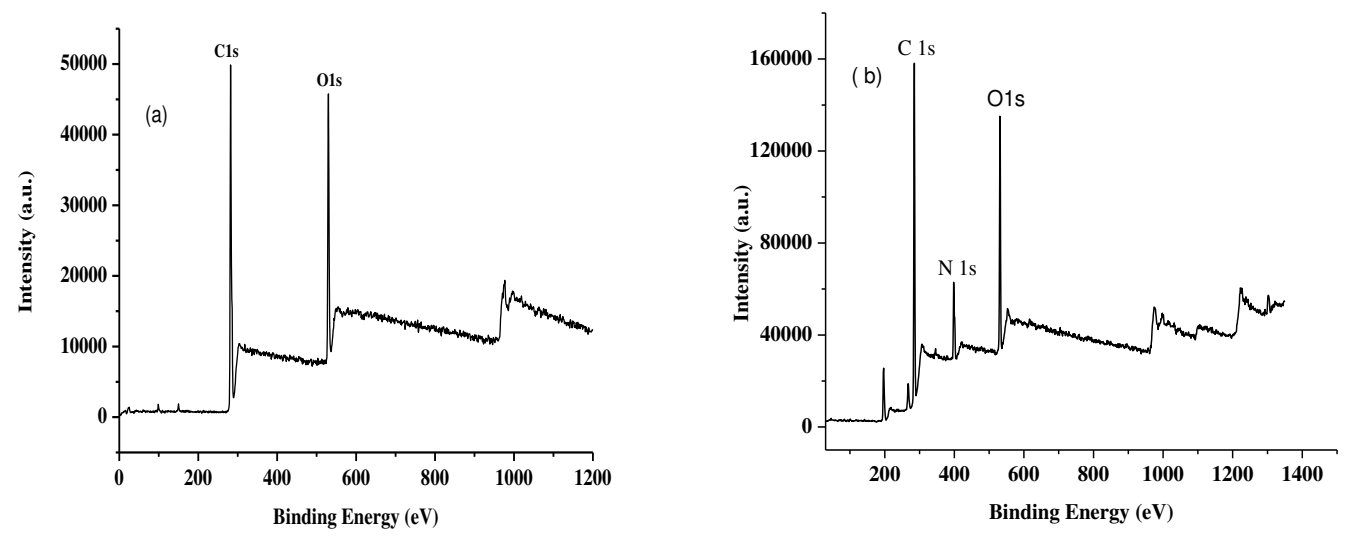

662
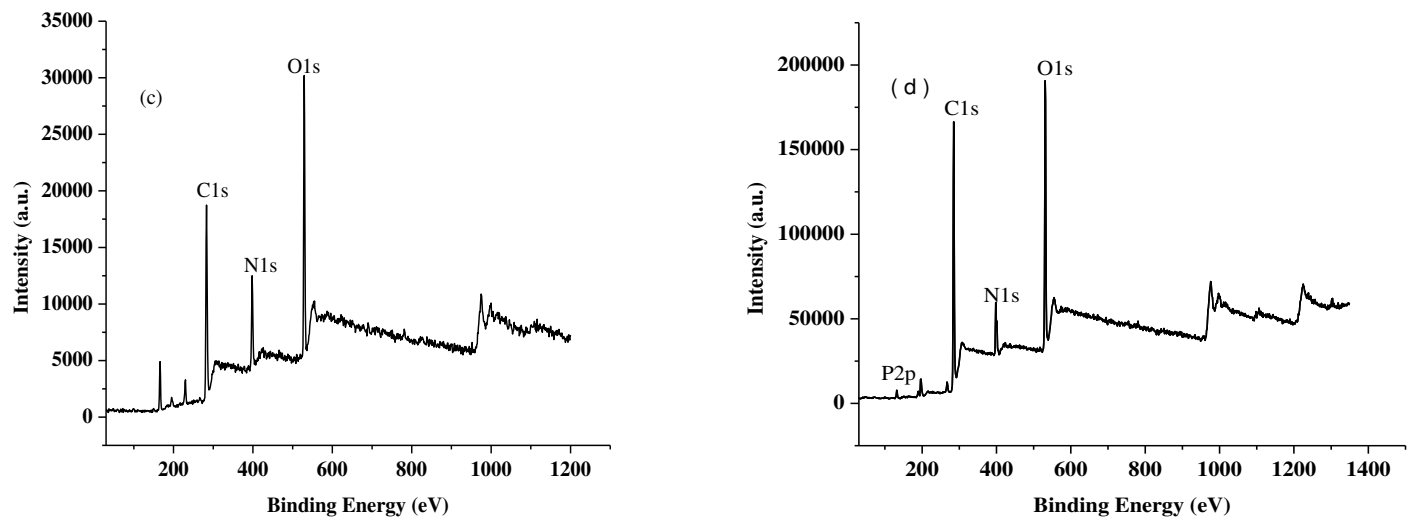

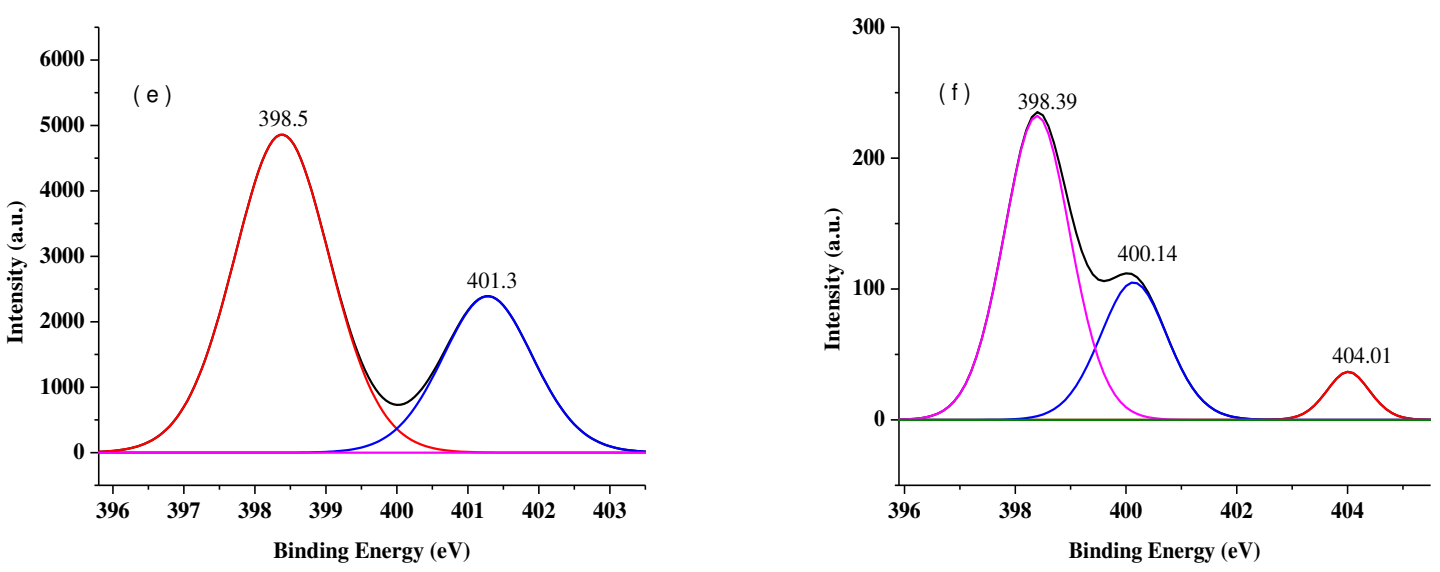

664
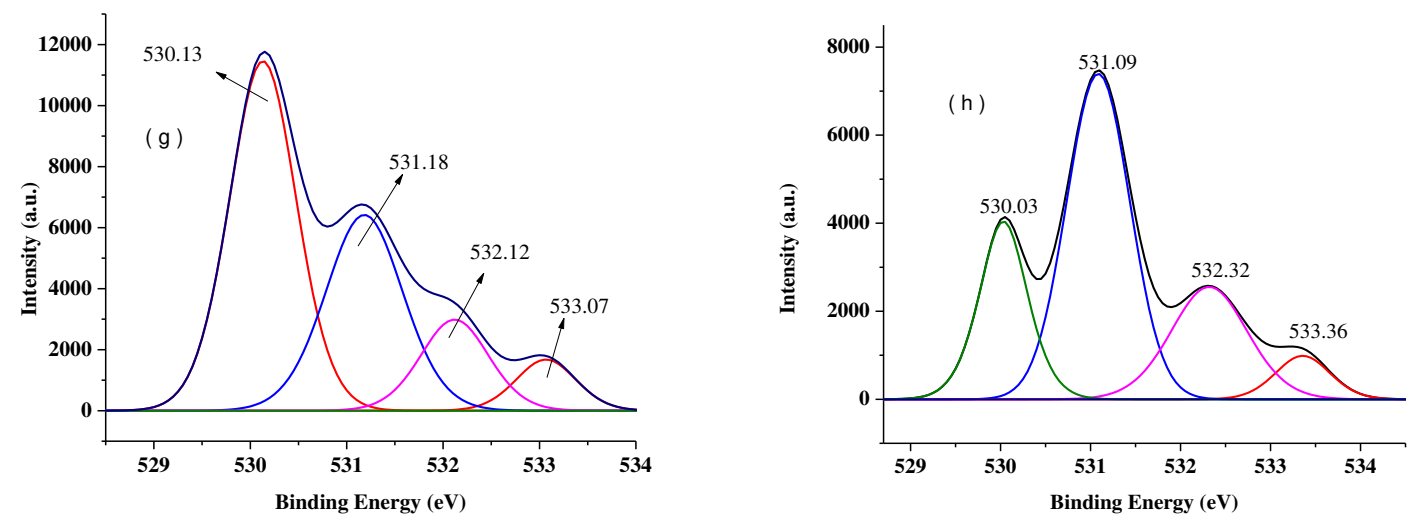

665
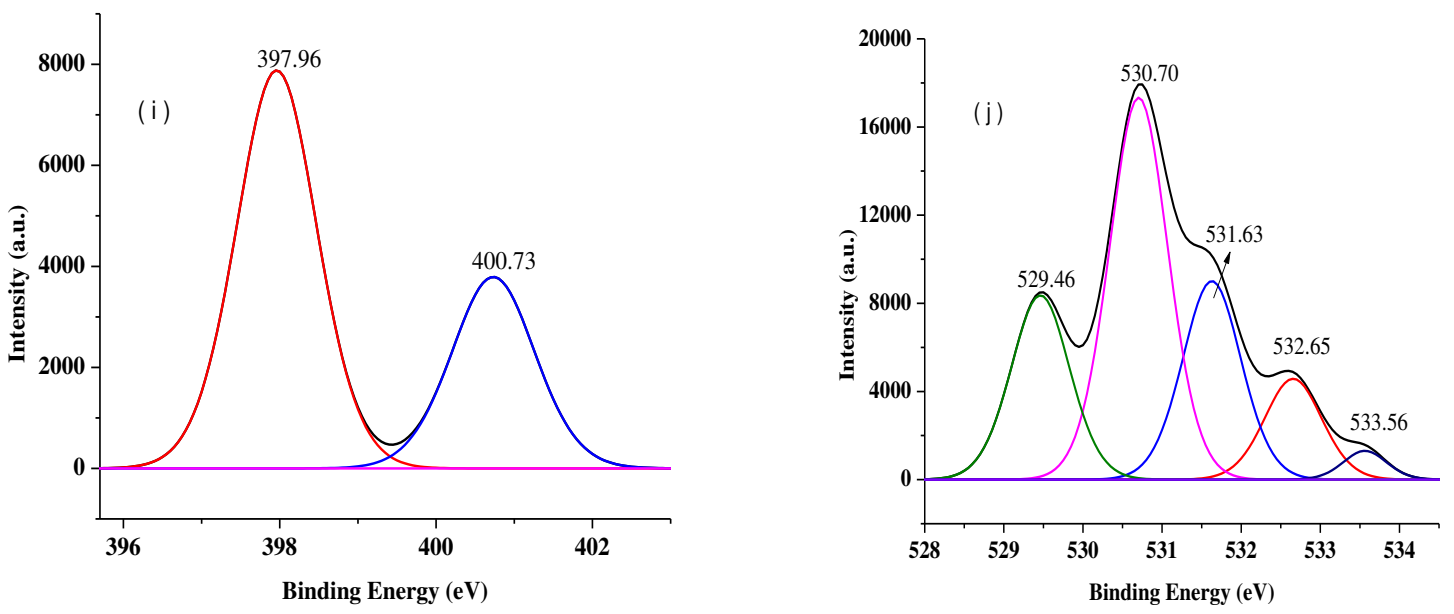
667

668

669

670

671

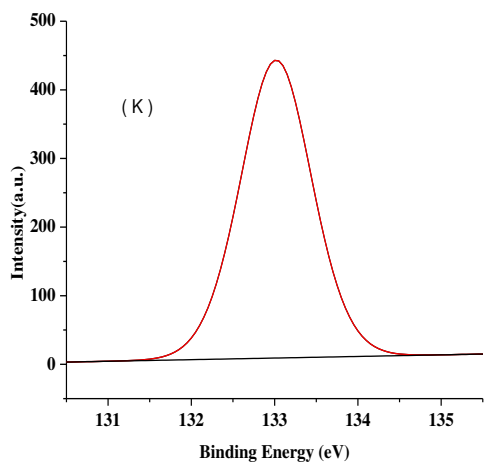

Fig. 8. XPS spectrum of WNS (a), ACWNS (b), ACWNS-NO ${ }_{3}^{-}$(c), ACWNS- $\mathrm{PO}_{4}{ }^{3-}$ (d); High resolution spectrum of N1s of ACWNS (e) before and (f) after $\mathrm{NO}_{3}{ }^{-}$adsorption; O1s spectrum of ACWNS ( $\mathrm{g}$ ) before and (h) after $\mathrm{NO}_{3}{ }^{-}$adsorption; N1s spectrum of ACWNS (i) after adsorption of $\mathrm{PO}_{4}{ }^{3-}$; (j) O1s spectrum of ACWNS- $\mathrm{NO}_{3}{ }^{-}$. (k ) P2p spectrum of ACWNS- $\mathrm{PO}_{4}{ }^{3-}$

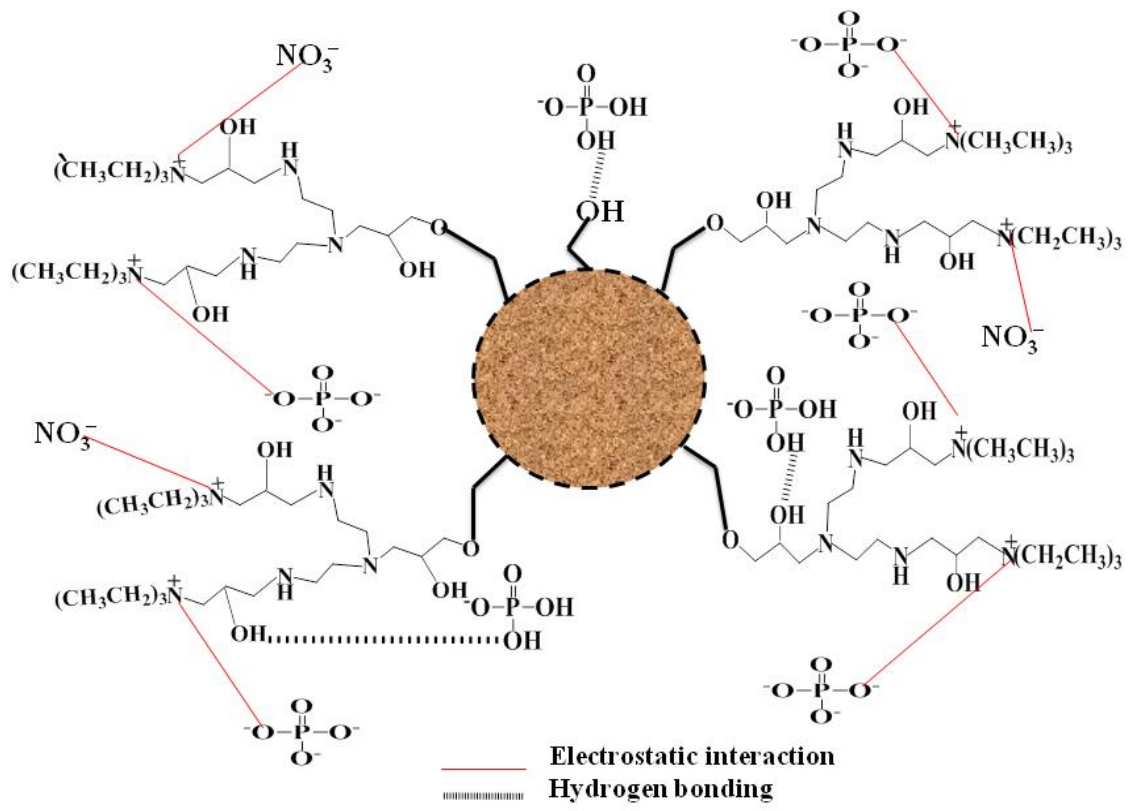

672

673 Fig. 9. Proposed schematic mechanism of $\mathrm{PO}_{4}{ }^{3-}$ and $\mathrm{NO}_{3}{ }^{-}$adsorption onto ACWNS. 
675 Table 1 Parameters of adsorption isotherms for $\mathrm{PO}_{4}{ }^{3-}$ and $\mathrm{NO}_{3}{ }^{-}$adsorbed onto ACWNS at varied temperatures

\begin{tabular}{|c|c|c|c|c|c|c|c|}
\hline \multirow{2}{*}{$\begin{array}{l}\text { Models } \\
T / \mathrm{K}\end{array}$} & \multirow[t]{2}{*}{ Parameters } & \multicolumn{3}{|c|}{ Phosphate } & \multicolumn{3}{|c|}{ Nitrate } \\
\hline & & 293 & 303 & 313 & 293 & 303 & 313 \\
\hline \multirow[t]{4}{*}{ Langmuir } & $q_{\mathrm{m}}\left(\mathrm{mg} \mathrm{g}^{-1}\right)$ & $82.2 \pm 4.8$ & $78.7 \pm 7.0$ & $70.6 \pm 6.1$ & $35.7 \pm 0.73$ & $24.8 \pm 0.61$ & $20.1 \pm 0.46$ \\
\hline & $K_{\mathrm{L}}\left(\mathrm{L} \mathrm{mg}^{-1}\right)$ & $0.0487 \pm 0.006$ & $0.0386 \pm 0.007$ & $0.0408 \pm 0.007$ & $0.0914 \pm 0.005$ & $0.108 \pm 0.009$ & $0.115 \pm 0.009$ \\
\hline & $R^{2}$ & 0.989 & 0.977 & 0.973 & 0.994 & 0.985 & 0.983 \\
\hline & $S S E$ & 23.7 & 41.0 & 40.1 & 3.45 & 3.38 & 2.22 \\
\hline \multirow[t]{4}{*}{ Freundlich } & $K_{\mathrm{F}}(\mathrm{mg} / \mathrm{g})(\mathrm{L} / \mathrm{mg})^{1 / \mathrm{n}}$ & $6.94 \pm 0.31$ & $5.66 \pm 0.22$ & $5.61 \pm 0.27$ & $7.09 \pm 1.01$ & $6.13 \pm 0.68$ & $5.46 \pm 0.66$ \\
\hline & $1 / n$ & $0.570 \pm 0.014$ & $0.582 \pm 0.012$ & $0.558 \pm 0.014$ & $0.364 \pm 0.041$ & $0.313 \pm 0.031$ & $0.289 \pm 0.034$ \\
\hline & $R^{2}$ & 0.996 & 0.997 & 0.996 & 0.914 & 0.931 & 0.906 \\
\hline & $S S E$ & 8.42 & 4.71 & 6.50 & 46.0 & 15.5 & 12.6 \\
\hline \multirow[t]{4}{*}{ Temkin } & $A$ & $-0.108 \pm 1.3$ & $-1.87 \pm 1.3$ & $-1.30 \pm 1.3$ & $-1.55 \pm 0.54$ & $1.08 \pm 0.55$ & $0.455 \pm 0.57$ \\
\hline & $B$ & $12.2 \pm 0.95$ & $11.3 \pm 0.85$ & $10.4 \pm 0.81$ & $7.98 \pm 0.28$ & $5.08 \pm 0.24$ & $4.32 \pm 0.23$ \\
\hline & $R^{2}$ & 0.948 & 0.951 & 0.948 & 0.989 & 0.981 & 0.975 \\
\hline & $S S E$ & 52.7 & 47.6 & 48.2 & 8.44 & 10.3 & 11.7 \\
\hline
\end{tabular}

676 Note: $S S E=\sum\left(q-q_{\mathrm{c}}\right)^{2}, q$ and $q_{\mathrm{c}}$ are the experimental value and calculated value according the model,

677 respectively.

678 
680 Table 2. Comparison of maximum adsorption capacities for uptake of $\mathrm{PO}_{4}{ }^{3-}$ and $\mathrm{NO}_{3}{ }^{-}$using different adsorbents

\begin{tabular}{llccc}
\hline Adsorbates & Adsorbents & Dosage $\left(\mathrm{g} \mathrm{L}^{-1}\right)$ & $q_{\mathrm{m}}\left(\mathrm{mg} \mathrm{g}^{-1}\right)$ & References \\
\hline Phosphate & Wood fiber treated with ferrous chloride & 2 & 5.3 & (Eberhardt et al., 2006) \\
& Zr-Loaded Carbon Nanotubes & 1 & 10.9 & (Gu et al., 2019) \\
& Iminodiacetic acid/Iron (III) & 1 & 33.7 & (Aryee et al., 2020) \\
& functionalized magnetic peanut husk & & & \\
& Modified Corn stalks & 2 & 22.9 & (Fan and Zhang, 2018) \\
& Sugarcane bagasse & 30 & 0.33 & (Ganesan et al., 2013) \\
& ACWNS & 1 & 78.7 & This work \\
\hline Nitrate & Surfactant-modified montmorillonite & 4 & 17.4 & (Bhardwaj et al., 2012) \\
& Surfactant-modified clinoptilolite & 4 & 16.9 & (Bhardwaj et al., 2012) \\
& Modified rice husk & 1 & 12.5 & (Katal et al., 2012) \\
& CPB modified zeolite & 4 & 2.11 & (Zhan et al., 2011) \\
Ammonium-Functionalized Mesoporous & 10 & 34.8 & (Hamoudi et al., 2007) \\
& Silica & & & \\
& ACWNS & 1 & 24.8 & This work \\
\hline
\end{tabular}

681

682 
684 Table 3 Parameters of Kinetic models for $\mathrm{PO}_{4}{ }^{3-}$ and $\mathrm{NO}_{3}{ }^{-}$adsorption onto ACWNS

\begin{tabular}{|c|c|c|c|c|c|c|}
\hline \multirow{2}{*}{$\begin{array}{l}\text { Adsorbate } \\
T / \mathrm{K}\end{array}$} & \multicolumn{3}{|c|}{ Phosphate } & \multicolumn{3}{|c|}{ Nitrate } \\
\hline & 293 & 303 & 313 & 293 & 303 & 313 \\
\hline \multicolumn{7}{|l|}{ Pseudo-first-order } \\
\hline$k_{1}\left(\mathrm{~g} \mathrm{mg}^{-1} \mathrm{~min}^{-1}\right)$ & $0.108 \pm 0.009$ & $0.104 \pm 0.006$ & $0.121 \pm 0.008$ & $0.335 \pm 0.035$ & $0.121 \pm 0.009$ & $0.140 \pm 0.009$ \\
\hline$\left.q_{\mathrm{e} \text { (theo }}\right)\left(\mathrm{mg} \mathrm{g}^{-1}\right)$ & $22.6 \pm 0.57$ & $21.6 \pm 0.38$ & $16.3 \pm 0.31$ & $17.7 \pm 0.35$ & $16.3 \pm 0.36$ & $14.1 \pm 0.23$ \\
\hline$q_{\mathrm{e}(\exp )}\left(\mathrm{mg} \mathrm{g}^{-1}\right)$ & 23.38 & 22.08 & 15.21 & 19.0 & 17.0 & 14.8 \\
\hline$R^{2}$ & 0.972 & 0.987 & 0.983 & 0.932 & 0.975 & 0.986 \\
\hline SSE & 11.9 & 5.21 & 3.90 & 9.45 & 5.44 & 2.55 \\
\hline \multicolumn{7}{|l|}{ Pseudo-second-order } \\
\hline$k_{2} \times 10^{-2}\left(\mathrm{~g} \mathrm{mg}^{-1} \mathrm{~min}^{-1}\right)$ & $0.47 \pm 0.038$ & $0.45 \pm 0.037$ & $0.74 \pm 0.058$ & $2.60 \pm 0.17$ & $0.747 \pm 0.06$ & $0.996 \pm 0.10$ \\
\hline$\left.q_{\mathrm{e} \text { (theo }}\right)\left(\mathrm{mg} \mathrm{g}^{-1}\right)$ & $26.8 \pm 0.50$ & $25.8 \pm 0.50$ & $19.2 \pm 0.33$ & $19.5 \pm 0.19$ & $19.1 \pm 0.33$ & $16.5 \pm 0.36$ \\
\hline$q_{\mathrm{e}(\mathrm{exp})}\left(\mathrm{mg} \mathrm{g}^{-1}\right)$ & 23.4 & 22.1 & 15.2 & 19.0 & 17.0 & 14.8 \\
\hline$R^{2}$ & 0.993 & 0.993 & 0.993 & 0.990 & 0.993 & 0.988 \\
\hline$S S E$ & 3.09 & 2.84 & 1.60 & 1.37 & 1.56 & 2.21 \\
\hline \multicolumn{7}{|l|}{ Elovich equation } \\
\hline$A$ & $2.87 \pm 0.61$ & $2.24 \pm 0.73$ & $2.24 \pm 0.49$ & $8.46 \pm 0.79$ & $2.37 \pm 0.42$ & $2.07 \pm 0.53$ \\
\hline$B$ & $5.23 \pm 0.21$ & $5.10 \pm 0.26$ & $3.80 \pm 0.17$ & $2.88 \pm 0.28$ & $3.76 \pm 0.15$ & $3.36 \pm 0.19$ \\
\hline$R^{2}$ & 0.982 & 0.973 & 0.978 & 0.906 & 0.983 & 0.968 \\
\hline$S S E$ & 7.71 & 11.2 & 5.07 & 13.1 & 3.75 & 5.78 \\
\hline \multicolumn{7}{|c|}{ Intra-particle diffusion model } \\
\hline $\begin{array}{l}K_{\mathrm{t} 1} /\left(\mathrm{mg} \mathrm{g} \mathrm{min}^{-1}\right) \\
C_{1} /\left(\mathrm{mg} \mathrm{g}^{-1}\right)\end{array}$ & $\begin{array}{l}4.59 \pm 0.23 \\
-0.168 \pm 0.60\end{array}$ & $\begin{array}{l}4.58 \pm 0.15 \\
-1.01 \pm 0.38\end{array}$ & $\begin{array}{l}3.11 \pm 0.21 \\
-0.872 \pm 0.71\end{array}$ & $\begin{array}{l}8.95 \pm 0.0 \\
-2.93 \pm 0.0\end{array}$ & $\begin{array}{l}3.64 \pm 0.17 \\
-0.513 \pm 0.44\end{array}$ & $\begin{array}{r}4.4 / \pm 0.05 \\
-2.83 \pm 0.11\end{array}$ \\
\hline$R^{2}$ & 0.995 & 0.996 & 0.980 & 1.00 & 0.992 & 1.00 \\
\hline$X^{2}$ & 0.274 & 0.112 & 0.387 & - & 0.149 & 0.00612 \\
\hline$K_{\mathrm{t} 2} /\left(\mathrm{mg} \mathrm{g}^{-1} \min ^{-1 / 2}\right)$ & $2.13 \pm 0.096$ & $2.13 \pm 0.10$ & $1.41 \pm 0.34$ & $1.68 \pm 0.11$ & $1.17 \pm 0.41$ & $0.944 \pm 0.16$ \\
\hline$C_{2} /\left(\mathrm{mg} \mathrm{g}^{-1}\right)$ & $9.54 \pm 0.48$ & $8.94 \pm 0.48$ & $7.86 \pm 1.7$ & $10.4 \pm 0.36$ & $8.98 \pm 2.2$ & $8.34 \pm 0.79$ \\
\hline$R^{2}$ & 0.998 & 0.999 & 0.944 & 0.988 & 0.801 & 0.925 \\
\hline$X^{2}$ & 0.00470 & 0.0047 & 0.060 & 0.0365 & 0.312 & 0.0848 \\
\hline$K_{\mathrm{t} 3} /\left(\mathrm{mg} \mathrm{g}^{-1} \min ^{-1 / 2}\right)$ & $0.382 \pm 0.31$ & $0.737 \pm 0.42$ & $0.461 \pm 0.015$ & $0.328 \pm 0.027$ & $0.0296 \pm 0.0$ & $0.133 \pm 0.0$ \\
\hline$C_{3} /\left(\mathrm{mg} \mathrm{g}^{-1}\right)$ & $20.6 \pm 2.2$ & $16.6 \pm 3.0$ & $13.4 \pm 0.11$ & $16.5 \pm 0.17$ & $16.8 \pm 0.0$ & $13.7 \pm 0.0$ \\
\hline$R^{2}$ & 0.597 & 0.754 & 0.999 & 0.981 & 1.00 & 1.00 \\
\hline SSE & 0.0995 & 0.179 & 0.000220 & 0.0036 & - & - \\
\hline
\end{tabular}


Table 4 Thermodynamic parameters for phosphate and nitrate adsorption on ACWNS

\begin{tabular}{cccccc}
\hline & & & & \multicolumn{3}{c}{$\Delta G^{\mathrm{o}}\left(\mathrm{kJ} \mathrm{mol}^{-1}\right)$} \\
& $\Delta H^{\mathrm{o}}\left(\mathrm{kJ} \mathrm{mol}^{-1}\right)$ & $\Delta S^{\mathrm{o}}\left(\mathrm{kJ} \mathrm{mol}^{-1} \mathrm{~K}^{-1}\right)$ & \multicolumn{3}{c}{} \\
\cline { 4 - 6 } & & & $293 \mathrm{~K}$ & $303 \mathrm{~K}$ & $313 \mathrm{~K}$ \\
\hline Phosphate & -9.46 & 0.021 & -3.43 & -3.05 & -3.01 \\
Nitrate & -17.8 & 0.053 & -2.15 & -2.09 & -1.09
\end{tabular}

690

691

692 Table 5 Statistical analysis for recovery of $\mathrm{PO}_{4}{ }^{3-}$ and $\mathrm{NO}_{3}^{-}$from the real water samples

\begin{tabular}{|c|c|c|c|c|c|}
\hline \multicolumn{2}{|c|}{ Environmental samples } & $\begin{array}{l}\text { Added } \\
\left(\mathrm{mg} \mathrm{L}^{-1}\right)\end{array}$ & $\begin{array}{c}\text { Detected } \\
\left(n=3, \mathrm{mg} \mathrm{L}^{-1}\right)\end{array}$ & $\begin{array}{l}\text { Recovery } \\
(\%, n=3)\end{array}$ & $\begin{array}{r}693 \\
\text { RSD }(\%)+694 \\
694\end{array}$ \\
\hline \multirow{8}{*}{ Phosphate } & \multirow[t]{4}{*}{ Lake water } & 0 & 0.108 & 100 & $2.0^{695}$ \\
\hline & & 5 & 5.06 & 99.2 & $2.4^{696}$ \\
\hline & & 10 & 9.96 & 98.6 & $6.9^{697}$ \\
\hline & & 15 & 14.9 & 98.3 & $3.1^{698}$ \\
\hline & \multirow[t]{4}{*}{ Tap water } & 0 & 0.09 & 100 & $7.0^{699}$ \\
\hline & & 5 & 5.10 & 100.3 & $5.4^{700}$ \\
\hline & & 10 & 10.1 & 100.3 & $2.5^{701}$ \\
\hline & & 15 & 14.7 & 97.3 & $1.3^{702}$ \\
\hline \multirow{8}{*}{ Nitrate } & \multirow[t]{4}{*}{ Lake water } & 0 & 2.45 & 99.2 & $8.3^{703}$ \\
\hline & & 5 & 6.9 & 90.0 & $4.4^{704}$ \\
\hline & & 10 & 11.9 & 95.3 & $1.3^{705}$ \\
\hline & & 15 & 16.1 & 91.0 & $4.0^{706}$ \\
\hline & \multirow[t]{4}{*}{ Tap water } & 0 & 1.03 & 99.3 & $3.0^{707}$ \\
\hline & & 5 & 5.9 & 97.0 & $2.0^{708}$ \\
\hline & & 10 & 10.6 & 92.6 & $2.0^{709}$ \\
\hline & & 15 & 14.6 & 90.6 & 3.9710 \\
\hline
\end{tabular}




\section{Highlights}

714 - Amine-grafted walnut shell (ACWNS) was prepared to bind phosphate and nitrate.

- Pseudo-second-order kinetics model described adsorption results.

- ACWNS exhibits excellent adsorption capacity.

- ACWNS can remove simultaneously phosphate and nitrate in a binary system.

- ACWNS showed prospect to be used in practical remediation of wastewater in real samples.

719

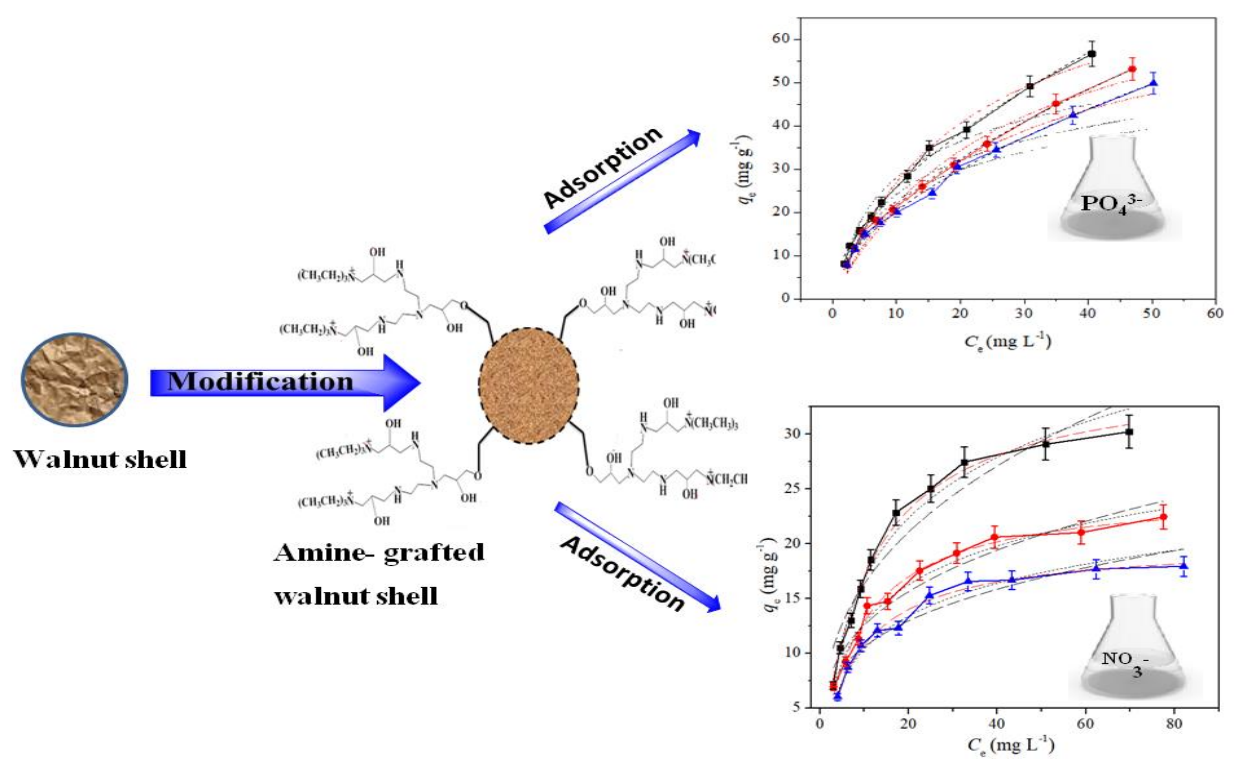

